University of Wollongong

Research Online

Faculty of Engineering and Information

Faculty of Engineering and Information

Sciences - Papers: Part A

Sciences

$1-1-2016$

\title{
Nano-enhanced phase change materials for improved building performance
}

Zhenjun Ma

University of Wollongong, zhenjun@uow.edu.au

Wenye Lin

University of Wollongong,w1950@uowmail.edu.au

Mohammed I. Sohel

University of Wollongong, msohel@uow.edu.au

Follow this and additional works at: https://ro.uow.edu.au/eispapers

Part of the Engineering Commons, and the Science and Technology Studies Commons

Research Online is the open access institutional repository for the University of Wollongong. For further information contact the UOW Library: research-pubs@uow.edu.au 


\title{
Nano-enhanced phase change materials for improved building performance
}

\author{
Abstract \\ Nano-enhanced phase change materials (PCMs) have attracted increasing attention to address one of the \\ key barriers (i.e. low thermal conductivity) to the wide adoption of PCMs in many industrial applications. \\ This paper discusses the generic problem and key issues associated with appropriately using this new \\ class of materials in buildings for effective thermal management and improved energy performance. An \\ overview on major recent development and application of nano-enhanced PCMs as thermal energy \\ storage media is provided. A case study based on a PCM ceiling ventilation system integrated with solar \\ photovoltaic thermal (PVT) collectors is then performed to evaluate the potential benefits due to the \\ dispersion of copper nanoparticles into the PCM base fluid of RT24. The results showed that this nano- \\ enhanced PCM has higher melting and solidification rates than that of the pure PCM. Compared to the \\ use of the pure PCM, $8.3 \%$ more heat was charged in and $25.1 \%$ more heat was discharged from the \\ nano-enhanced PCM under the three winter test days. More research is needed to understand the \\ fundamental mechanisms behind the PCM thermal conductivity enhancement through the dispersion of \\ nanometer-sized materials and to investigate how these mechanisms drive building performance \\ enhancement. \\ Keywords \\ enhanced, phase, nano, change, performance, materials, improved, building \\ Disciplines \\ Engineering | Science and Technology Studies \\ Publication Details \\ Ma, Z., Lin, W. \& Sohel, M. Imroz. (2016). Nano-enhanced phase change materials for improved building \\ performance. Renewable and Sustainable Energy Reviews, 58 1256-1268.
}

This journal article is available at Research Online: https://ro.uow.edu.au/eispapers/4870 


\title{
Nano-Enhanced Phase Change Materials for Improved Building
}

\section{Performance}

\author{
Zhenjun Ma*, Wenye Lin, M. Imroz Sohel \\ Sustainable Buildings Research Centre (SBRC), Faculty of Engineering and Information \\ Sciences, University of Wollongong, New South Wales (NSW), 2522, Australia \\ *Phone: (61) 024221 4143; Email: zhenjun@uow.edu.au
}

\begin{abstract}
Nano-enhanced phase change materials (PCMs) have attracted increasing attention to address one of the key barriers (i.e. low thermal conductivity) to the wide adoption of PCMs in many industrial applications. This paper discusses the generic problem and key issues associated with appropriately using this new class of materials in buildings for effective thermal management and improved energy performance. An overview on major recent development and application of nano-enhanced PCMs as thermal energy storage media is provided. A case study based on a PCM ceiling ventilation system integrated with solar photovoltaic thermal (PVT) collectors is then performed to evaluate the potential benefits due to the dispersion of copper nanoparticles into the PCM base fluid of RT24. The results showed that this nano-enhanced PCM has higher melting and solidification rates than that of the pure PCM. Compared to the use of the pure PCM, $8.3 \%$ more heat was charged in and 25.1\% more heat was discharged from the nano-enhanced PCM under the three winter test days. More research is needed to understand the fundamental mechanisms behind the PCM thermal conductivity enhancement through the dispersion of nanometer-sized materials and to investigate how these mechanisms drive building performance enhancement.
\end{abstract}

Keywords: Nanometer-sized materials; Phase change materials; Thermal energy storage; Building performance; Case study 


\section{Contents}

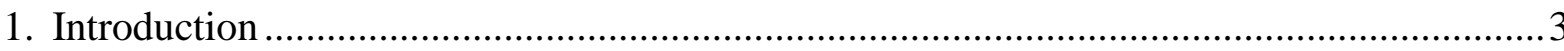

2. Generic problem for development and application of nano-enhanced PCMs in buildings ..4

2.1. Material selection, preparation and thermal characterization .....................................

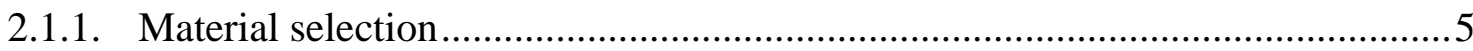

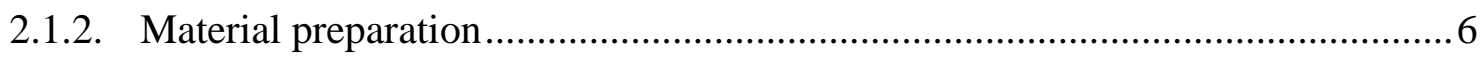

2.1.3. Material thermal characterization ........................................................... 6

2.2. Examination of thermal conductivity enhancement and phase change energy transport

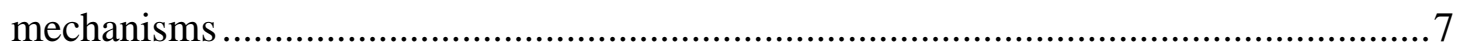

2.3. Investigation of building thermodynamic behavior and performance enhancement due

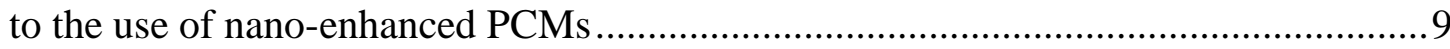

3. Research and application of nano-enhanced PCMs as thermal energy storage media ....... 10

3.1. Research on material preparation and thermal characterization ............................... 10

3.1.1. Nano-enhanced PCMs with paraffin as the base fluid ..................................... 10

3.1.2. Nano-enhanced PCMs with other PCMs as base fluids................................... 13

3.2. Numerical and experimental investigation on thermodynamic behavior and melting/solidification characteristics of nano-enhanced PCMs ................................ 15

3.3. Application of nano-enhanced PCMs in buildings ............................................... 19

4. Case study of using nano-enhanced PCMs in a building ceiling ventilation system ..........22

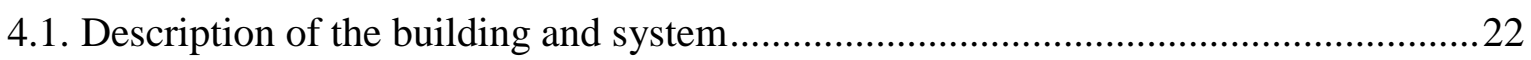

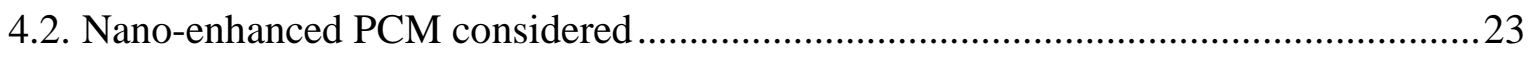

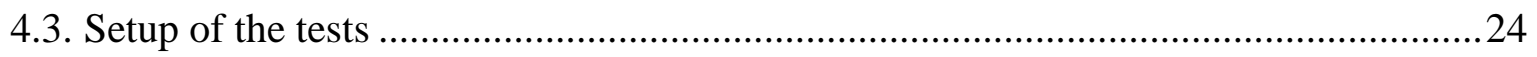

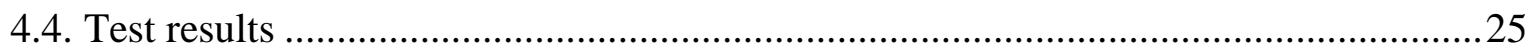

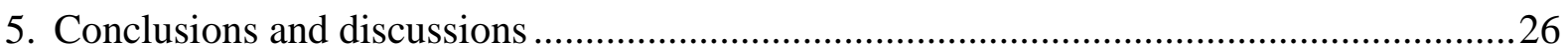

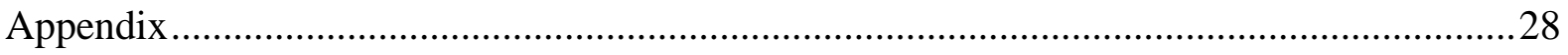

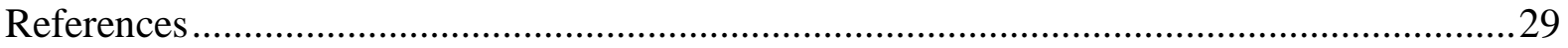




\section{Introduction}

Buildings are the major energy consumers and account for as much as $45 \%$ of global energy consumption [1]. Enhancing building energy efficiency is therefore essential to reduce the global energy use, mitigate the global warming, promote the environmental sustainability and improve the security of energy supplies.

Over the last two decades, significant efforts have been made on the development and application of various low energy technologies to promote building energy efficiency [2-5]. Among different technologies, phase change materials (PCMs) have attracted wide attention for developing high performance and energy efficient buildings [6-9]. PCMs are substances that can absorb, store and release a large amount of thermal energy at relatively constant temperatures [10] and are well suited for heat transfer and energy conversion applications. PCMs can also be used to develop high performance electronic devices and smart textiles $[11,12]$, store solar energy for space heating, cooking and industrial process heating applications $[13,14]$, and smooth the exothermic temperature peaks in chemical reactions [15].

Thermal performance of a PCM is broadly characterized by the melting temperature, energy storage density and thermal conductivity [16]. For proper function of a PCM based thermal energy system, the rapid melting and solidification of the PCM is desirable. However, many conventional PCMs, especially organic PCMs, have a significant disadvantage of low thermal conductivity and are difficult to address the rapid load changes during the thermal charging and discharging processes [17-19]. To overcome this problem, a number of heat transfer enhancement techniques have been proposed such as the use of fins and heat pipes [10, 20], insertion and dispersion of high thermal conductive materials [17], micro- and macro-encapsulation [10, 21], the application of multiple PCMs [22], etc. Among these techniques, the dispersion of high thermal conductive nanometer-sized materials, such 
as nanoparticles, nanofibers, nanotubes and nanosheets, in the PCM base fluid to significantly increase its thermal conductivity and enhance the capability of energy exchange is currently receiving increasing interest [16-19]. This emerging mixture is called nano-enhanced phase change material (PCM) herein.

The first study on the use of nanometer-sized materials (i.e. nanofibers) in PCMs for improved thermal energy storage was reported by Elgafy and Lafdi [23] in 2005. Since then, the efforts have been made on the development and preparation of appropriate nano-enhanced PCMs suitable for various industrial applications, test and characterization of their thermal energy storage performance, and investigation of their melting and solidification characteristics. The aim of this paper is to provide an overview on major recent research and development in this field, and a few recommendations of future work in this direction. The generic problem and key issues related to the appropriate use of this new class of materials in buildings for improved indoor thermal performance and enhanced energy efficiency will be discussed. A case study is also provided to illustrate the potential benefits of using a nanoenhanced PCM into a building ceiling ventilation system.

\section{Generic problem for development and application of nano-enhanced PCMs in buildings}

Similar to PCMs, nano-enhanced PCMs can be used in building fabric as part of building structure for lightweight or even heavyweight buildings to increase the overall and local building thermal mass. They can also be incorporated into building heating, ventilation and air-conditioning (HVAC) systems as centralized or distributed energy storage systems to decrease the mismatch between the energy supply and demand through significant peak load shifting and reduction. The performance enhancement of buildings using nano-enhanced PCMs is a complex situation for investigation and optimization as there are many variables and significant uncertainties involved in building physics. The unknown speed of the moving 
solid-liquid interface, the interaction of nanometer-sized materials with PCM base fluids, and the highly nonlinear phase change characteristics make it extremely difficult to deal with the phase change problem and reliably estimate the flow and energy transport mechanisms when the materials undergo the phase transition in the melting and solidification cycles.

Fig. 1 illustrates a general framework towards appropriate development and optimization of nano-enhanced PCMs for building applications. It mainly consists of three steps, including material selection, preparation and thermal characterization (Step 1), examination of thermal conductivity enhancement and phase change energy transport mechanisms (Step 2), and investigation of building thermodynamic behavior and performance enhancement due to the use of nano-enhanced PCMs (Step 3).

\subsection{Material selection, preparation and thermal characterization}

\subsubsection{Material selection}

The selection of appropriate PCMs and nanometer-sized materials is essential to develop effective nano-enhanced PCMs. For building applications, PCMs used should have a melting temperature in the desired range of building practical operation. The first approximation proposed by Peippo et al. [24], as shown in Equation (1), could be useful for determining the near optimal melting temperature of PCMs $\left(T_{P C M, o p t}\right)$ to be used in building envelopes. PCMs to be considered for building applications should have large latent heat of fusion, high specific heat and thermal conductivity, minimum sub-cooling, and be chemically stable, nontoxic, non-flammable and non-corrosive $[25,26]$. A summary of major PCMs suitable for building applications can be found in Refs. [7, 25-27].

$$
T_{P C M, \text { opt }}=\frac{t_{d} T_{d}+t_{n} T_{n}}{t_{d}+t_{n}}+\frac{Q}{h t_{s t o r}}
$$

where, $Q$ is the heat absorbed by the unit area of the room surface $\left(\mathrm{J} / \mathrm{m}^{2}\right), h$ is the average heat transfer coefficient between the wall surface and surroundings $\left(\mathrm{W} / \mathrm{m}^{2} /{ }^{\circ} \mathrm{C}\right), T_{d}$ is the room 
daytime temperature $\left({ }^{\circ} \mathrm{C}\right), T_{n}$ is the room night-time temperature $\left({ }^{\circ} \mathrm{C}\right), t_{d}$ is the charging time $(s), t_{n}$ is the discharging time $(s)$, and $t_{s t o r}$ is the diurnal storage cycle equaling $t_{d}+t_{n}(s)$.

The nanometer-sized materials to be used can be either metallic or non-metallic. A number of nanometer-sized materials such as copper, copper oxide, aluminum, alumina, titania, silver, silica, carbon nanotubes, graphite nanofibers, etc., have been used to develop nano-enhanced PCMs for various applications [17, 28, 29]. High thermal conductive nanometer-sized materials can enhance the thermal conductivity of PCMs. However, their volume fractions in the PCM base fluid should be minimized in order to maximize the overall energy storage capacity [16, 17], which is therefore a critical variable required to be optimized when using nano-enhanced PCMs in buildings.

\subsubsection{Material preparation}

Nano-enhanced PCMs can be prepared by using either one-step method or two-step method. In one-step method, the material is prepared through simultaneously producing and dispersing nanometer-sized materials into the PCM base fluid [30, 31], while in the two-step method, nanometer-sized materials are first produced and then dispersed into the PCM base fluid $[31,32]$. The two-step method is the most economic method to produce the materials in large scale and has been extensively used to prepare nano-enhanced PCMs [31, 33-36]. In this method, the ultrasonic vibration technique is usually used to ensure that nanometer-sized materials are well dispersed into the base fluid [33-36] and appropriate surfactants are used to enhance the stability of nanometer-sized materials in the PCM base fluid to maintain good suspension performance $[33,36]$.

\subsubsection{Material thermal characterization}

Due to the inherent randomness of dispersed nanometer-sized materials in the PCM base fluid, micro-structures such as size, geometry and volume fraction of nanometer-sized materials will influence the thermo-physical properties of the mixture. Therefore, the thermal 
properties of nano-enhanced PCMs with different sizes, geometries and volume fractions of nanometer-sized materials should be measured in order to determine the best mixture. The thermal properties of nano-enhanced PCMs can be characterized by using a wide range of techniques and some commonly used techniques [7, 33, 37-41] are summarized in Table 1. As the key purpose of the dispersion of nanometer-sized materials into the PCM base fluid is to significantly increase its thermal conductivity, thermal conductivity is therefore one of the most important parameters for characterizing the thermal transport properties of nanoenhanced PCMs. The thermal conductivity of nano-enhanced PCMs can be measured using either steady-state methods or transient-state methods [42]. Guarded hot plate method is a typical example of the steady-state method while transient hot wire method, laser flash method and transient plane source method are among the typical transient-state methods [42, 43]. The key differences among these test methods are the sample preparation, sample size, testing time, training time, measurement methodology, etc.

Based on the thermal characterization, the correlations between the thermal conductivity and the size, geometry and volume fraction of the selected nanometer-sized material in the PCM base fluid can be established. The best mixture with optimal size, geometry and volume fraction of the nanometer-sized material in the base fluid can then be determined based on the correlations developed.

\subsection{Examination of thermal conductivity enhancement and phase change energy transport}

\section{mechanisms}

To maximize the benefits of using nano-enhanced PCMs in building applications, it is essential to understand the fundamental mechanisms of how nanometer-sized materials drive the thermal conductivity enhancement of PCMs and affect the phase change energy transport process. These fundamental mechanisms can be examined on both atomic/molecular scale and macroscopic scale. 
On the atomic/molecular scale, advanced molecular simulation methods can be used to describe the thermal properties of nano-enhanced PCMs to provide detailed and important information on their energy transport mechanisms and help understand the basic physics behind the thermal conductivity enhancement due to the dispersion of nanometer-sized materials into the PCM base fluid. Molecular dynamics simulation, as one of the most detailed molecular simulation methods which can compute the motion of individual molecules, has been commonly used to understand the microscopic behaviors of various materials [44-46]. Rao et al. [47], for instance, employed molecular dynamics simulation to investigate the melting mechanisms of nano-encapsulated PCMs. Babaei et al. [48] used molecular dynamics simulation to investigate the thermal conductivity enhancement of paraffin with carbon based nano-fillers. Sarkar and Selvam [49] studied the enhanced thermal transport mechanism of nanofluids by using molecular dynamics simulation. Li et al. [50] investigated molecular layering at the liquid-solid interface of nanofluids by equilibrium molecular dynamics simulation.

On the macroscopic scale, two numerical methods can be used, including the fronttracking method and the fixed-gird enthalpy method [51]. As the phase change usually occurs over a mushy zone where a distinct solid-liquid interface may not be clearly identified, the fixed-grid enthalpy method is therefore commonly used [52, 53]. In the enthalpy-based approach, the solid-liquid interface is not simultaneously tracked but derived from the calculated temperature distributions [51]. Zhao et al. [54], for instance, investigated a high temperature energy storage using encapsulated PCMs for concentrated solar power applications. Both the front-tracking approach and enthalpy-porosity approach were used for numerical simulations. It was shown that the results predicted by both methods agreed with each other. Bhattacharya et al. [55] used the enthalpy method to solve one-dimensional phase 
change problems. The single energy balance equation was solved for the entire domain consisting of solid, liquid and mushy zones.

On the macroscopic scale, sophisticated and well-designed experimental test facilities are also valuable for investigating the thermal conductivity enhancement and energy transport mechanisms of nano-enhanced PCMs. The combination of both molecular scale simulation and macroscopic scale simulation may help identify extra functionalities of nano-enhanced PCMs for effective thermal management and system performance enhancement..

\subsection{Investigation of building thermodynamic behavior and performance enhancement due to the use of nano-enhanced PCMs}

The successful use of nano-enhanced PCMs in buildings depends on many factors, which include but not limited to the type and amount of the materials used, the method of integrating nano-enhanced PCMs into buildings, building/system design philosophy, control strategies for load management, utility rate structure, climatic condition, etc.

For a given project, the selection of an appropriate method for integrating nano-enhanced PCMs into buildings is one of the key steps. As mentioned earlier, nano-enhanced PCMs can be integrated either with building envelopes to increase building thermal mass or with HVAC systems as a thermal energy storage system. A wide range of methods on how to integrate PCMs into buildings have been reported in previous studies $[6,56]$ and many of them are also suitable for nano-enhanced PCMs. It is worthwhile to point out that nanometer-sized materials usually have a toxic effect on human beings and environment. Special care should be taken when using nano-enhanced PCMs and the methods used to integrate nano-enhanced PCMs into buildings are therefore critically important. Once the way of integrating nanoenhanced PCMs into buildings has been determined, the next step is to select a nanoenhanced PCM with appropriate phase change temperature suitable for this particular application. Then, a good understanding of the thermodynamic behavior of the 
building/system under the ever-changing working conditions is needed to identify building temperature response characteristics, and system level and subsystem level interactions. This can be achieved through numerical simulations and/or experimental investigation. Advanced control strategies for effective load management can then be developed to maximize the benefits of using this new class of materials in buildings. It is worthwhile to note that control strategies for load management should be developed by taking into account utility rate structure, characteristics of nano-enhanced PCMs used, local climatic conditions and building load profile. With control strategies developed, the performance enhancement of the building using nano-enhanced PCMs can be quantitatively evaluated.

\section{Research and application of nano-enhanced PCMs as thermal energy storage media}

In this section, the research on preparation and thermal characterization of nano-enhanced PCMs, numerical and experimental investigation on their thermal behavior and melting/solidification characteristics, and application of nano-enhanced PCMs in buildings is presented, which intends to summarize major recent studies and provide some useful information for appropriate use of this new class of materials in buildings. Detailed review on thermal conductivity enhancement of PCMs as thermal energy storage media including the use of nanostructure-based materials can be found in the articles presented by Khodadadi et al. $[17,57]$.

\subsection{Research on material preparation and thermal characterization}

\subsubsection{Nano-enhanced PCMs with paraffin as the base fluid}

Paraffin has demonstrated very good storage performance in various applications and is one of the most commonly used organic PCMs [7, 13, 41]. A number of studies have used various nanometer-sized materials to improve the thermal conductivity of paraffin. The dispersion of copper nanoparticles in paraffin was reported by Wu et al. [19, 34]. Hitenol BC10 was used as the surfactant. The measurement using the Fourier transform infrared (FTIR) 
spectrometer showed that physical interactions existed among copper nanoparticles, paraffin and Hitenol BC-10. Compared to the pure paraffin, the melting time and solidification time of the mixture with a weight fraction of $1.0 \%$ copper nanoparticles were reduced by $33.3 \%$ and $31.6 \%$, respectively.

Teng and $\mathrm{Yu}$ [28] reported on the preparation of nano-enhanced PCMs by mixing paraffin with alumina, titania, silica and zinc oxide particles, respectively. The heat conduction and differential scanning calorimeter (DSC) experiments showed that, among the four types of particles, paraffin mixed with titania provided better heat conduction and thermal storage performance. Ho and Gao [41] investigated the thermo-physical properties of paraffin with alumina nanoparticles. It was shown that the thermal conductivity and dynamic viscosity of the mixture increased nonlinearly with the increase of the mass fraction of alumina nanoparticles. Paksoy and Sahan [58] examined the thermal enhancement of paraffin dispersed with magnetite nanoparticles with the particle size in the range of 15-25 $\mu \mathrm{m}$ for solar applications. The result showed that the thermal energy storage capacity of paraffin increased by $20 \%$ through adding $10 \%$ magnetite nanoparticles.

Paraffin mixed with copper oxide nanoparticles was prepared by Sheikh and Sharif [59]. Three methods, i.e. distillation under atmospheric and reduced pressure, mixing with alcohol mixture solvent, and high speed centrifugation, were investigated for separation of nanoparticles from paraffin before its disposal after long term application cycles considering that nanoparticles have a negative impact on human beings and environment. The results showed that the first two methods have low and moderate equipment costs and high separation efficiencies while the third one has a high equipment cost and a moderate separation efficiency.

Several studies used graphite as the nanometer-sized material to enhance the thermal conductivity of paraffin. Ji et al. [16], for instance, demonstrated that embedding continuous 
ultrathin-graphite foams (UGFs) with a volume fraction of $1.2 \%$ in paraffin wax can increase its thermal conductivity by up to 18 times. Randomly dispersing graphite nanoparticles in paraffin showed that the thermal conductivity of the mixture increased from around 0.350 to $0.9362 \mathrm{~W} / \mathrm{m} \cdot \mathrm{K}$ while the latent heat of fusion decreased from 209.33 to $181.81 \mathrm{~J} / \mathrm{g}$ when the weight fraction of graphite nanoparticles varied from 0 to $10 \%$ [60]. Ehid et al. [61] presented a method to prevent graphite nanofiber settling in paraffin by using high density polyethylene as a stabilizing polymer. It was indicated that graphite nanofiber settling can be reduced or even eliminated when the weight fraction of high density polyethylene was $10 \%$. Fan et al. [62] and Yu et al. [63] examined the effect of suspending small quantities of carbon nanofillers, including short and long multi-walled carbon nanotubes, carbon nanofibers and graphene nanoplatelets (GNPs), in paraffin wax. It was shown that, compared to the base fluid, the thermal conductivity of the mixture dispersed with a $10 \%$ weight faction of GNPs increased up to $164 \%$ owning to the reduced thermal interface resistance [62]. Shi et al. [64] reported that the thermal conductivity of paraffin increased by more than 10 times by adding exfoliated graphite nanoplatelets with a weight fraction of $10 \%$. The results from Warzoha $e t$ al. [65] showed that, through dispersion of herringbone style graphite nanofibers into a paraffin PCM, the thermal conductivity of the mixture in the solid phase increased exponentially while that in the liquid phase did not change dramatically until the nanoparticles reached a critically dense state.

Cui et al. [66] investigated the thermal conductivity enhancement of paraffin wax and soy wax through dispersing carbon nanofibers (CNFs) and carbon nanotubes (CNTs). It was shown that both CNFs and CNTs can increase the thermal conductivity of the mixtures, while CNFs is more effective than CNTs due to its better dispersion performance. The above results indicated that the dispersion of highly thermal conductive nanometer-sized materials in paraffin can substantially increase its thermal conductivity, assisting in overcoming the key 
barrier towards its wide application as thermal energy storage media. However, the effect of nanometer-sized materials on human health and environment was not considered in most of these studies.

\subsubsection{Nano-enhanced PCMs with other PCMs as base fluids}

A number of studies also investigated the dispersion of nanometer-sized materials into other types of PCMs rather than paraffin to enhance their thermophysical performance. For instance, the dispersion of graphite and nickel particles into erythritol was reported by Oya $e t$ al. [29]. The measurement results using the laser flash method showed that the thermal conductivity of the mixture increased gradually with the increase of the volume fraction of the particles and their aspect ratio. The variation of the thermal conductivity could be explained well by Nielsen's equation. He et al. [33] presented a study on dispersing titania nanoparticles in the saturated barium chloride aqueous solution. The measurements showed that the thermal conductivity of the mixture almost linearly increased while its super-cooling degree decreased with the increase of the volume fraction of the nanoparticles.

The preparation of the copper oxide/oleic acid nano-enhanced PCM using a two-step method was reported by Harikrishnan and Kalaiselvam [35]. Compared to the base fluid, the melting time and solidification time of the mixture were reduced by 28.57 and $27.67 \%$ respectively, when the weight fraction of copper oxide nanoparticles was $2.0 \%$. Another study from Harikrishnan et al. [67] by suspending titania nanoparticles in stearic acid showed that the melting and solidification times of the mixture reduced by 7.03-43.72 and 6.62$41.39 \%$ respectively when the weight fraction of the nanoparticles varied from $0.05 \%$ to $0.3 \%$, compared to the stearic acid base fluid.

Nano-composite PCM microcapsules with bromo-hexadecane and silver nanoparticles were prepared by Song et al. [68] for textile manufacturing processes. The thermogravimetric analysis showed that nano-composite PCM microcapsules can maintain undamaged structure 
with a total weight loss of $10-15 \%$ while the conventional PCM microcapsules were destroyed and collapsed at $130^{\circ} \mathrm{C}$. The effect of silver nanoparticles on the thermal conductivity of 1-tetradecanol was investigated by Zeng et al. [69]. The results indicated that there was no strong interaction between the silver nanoparticles and the PCM base fluid. The thermal conductivity of the mixture increased with the increase of the loading of the silver nanoparticles.

Cai et al. [70] examined the effects of silica nanoparticles on the PCM composite fibers consisting of lauric acid and polyethylene terephthalate. The results from the measurements showed that the crystallization of lauric acid and the heat enthalpy of the composite fibers were influenced by the loading of the silica nanoparticles. The particle sized used was around $20 \mathrm{~nm}$.

The dispersion of nanoparticles in water was also reported. The results from $\mathrm{Wu}$ et al. [71] by using alumina nanoparticles showed that the addition of alumina can substantially decrease the super-cooling degree of water. The solidification time of the mixture can reduce by $20.5 \%$ when the weight fraction of alumina nanoparticles was $0.2 \%$. The results from Mo et al. [72] by suspending carbon nanotubes (CNTs) in deionized water indicated that the solidification behavior of the mixture was influenced by its nucleation and stability.

The aforementioned studies showed that nanometer-sized materials with a high surfaceto-volume ratio can change the energy transport properties of PCMs. Nano-enhanced PCMs exhibited much better thermo-physical properties than that of the PCM base fluids. The improved thermal conductivity can enhance the thermal energy storage capability of nanoenhanced PCMs and facilitate the effective thermal management in various applications. 


\subsection{Numerical and experimental investigation on thermodynamic behavior and melting/solidification characteristics of nano-enhanced PCMs}

As mentioned earlier, there are many variables and factors influencing the performance of thermal energy storage systems when using nano-enhanced PCMs as the thermal storage media. A better understanding of the effects of these variables and factors on the thermodynamic behavior and heat transfer characteristics of nano-enhanced PCMs is therefore essential to help develop highly effective thermal energy storage systems.

Jesumathy et al. [73] developed an experimental setup and investigated the heat transfer characteristics of a vertical annulus energy storage system with paraffin dispersed with copper oxide nanoparticles. It was shown that the heat transfer coefficient of paraffin during the solidification was increased by $78 \%$ for the maximum flow rate of $10 \mathrm{~L} / \mathrm{min}$ when the weight fraction of copper oxide particles was $10 \%$, compared to that of the pure paraffin wax.

Fan et al. $[74,75]$ investigated the unidirectional freezing of a nano-enhanced PCM with cyclohexane and copper oxide nanoparticles by using one-dimensional Stefan model and an experimental setup. It was concluded that the unidirectional freezing was enhanced by $5.2 \%$ when the weight fraction of the copper oxide nanoparticles was $2.0 \%$ and the freezing was slowed down when the weight fraction of the nanoparticles increased to $4.0 \%$ [75]. Based on the similar experimental setup, Zeng et al. [39] experimentally studied the melting characteristics of 1-dodeconal dispersed with multi-walled carbon nanotubes (CNTs). It was shown that the thermal conductivity of the mixture increased nearly linearly with the increase of the amount of the CNTs used. However, natural convection during the melting process was suppressed significantly due to the increased viscosity. The natural convection effect on the melting process of nano-enhanced PCMs in porous enclosure was studied by Tasnim et al. [76] and Hossain et al. [77]. The scale analysis showed that there were four regimes involved in the melting process of the nano-enhanced PCMs, including the conduction regime, 
transition regime, convection regime and variable height regime [76]. Incorporating more nanoparticles reduced the energy requirement to complete the melting process [77].

Weinstein et al. [78] experimentally explored the thermal management of electronics by embedding graphite nanofibers (GNFs) into paraffin wax by using a cube supplied with a constant heat flux to its bottom surface. It was shown that the transient thermal response of the mixture was influenced by the weight fraction and shape of GNFs (i.e. herringbone, ribbon and platelet). The thermal response was first improved with the loading of the GNFs. However, Rayleigh-Bénard convection will be suppressed and the PCM will be overheated near the heat source when the weight fraction of GNFs increased to a certain value. Based on the similar test unit (i.e. cubic thermal containment unit), Sanusi et al. [79] examined the energy storage and solidification of n-tricosane embedded with GNFs for electronics applications. It was found that the addition of GNFs can significantly delay the time for the PCM to reach its melting temperature. The difference in the heat-up time between the mixture and the base fluid increased with the increase of the aspect ratio of the thermal containment unit.

An experimental and numerical study on the melting of n-octadecane dispersed with copper oxide nanoparticles in a square enclosure, an annular cavity and a horizontal cylindrical vessel was reported by Dhaidan et al. [80-82]. The commercial software COMSOL was used to numerically solve the governing equations. The results based on a square enclosure experimental setup and the COMSOL simulation showed that the parallelto-wall flat shape interface was existed at the lower part of the test cell which was dominated with the conduction heat transfer, while the curved shape interface was developed at the upper part of the test cell dominated with natural convection [80]. For both annular cavity and horizontal cylindrical vessel, it was found that conduction was dominant at the early stage of 
the melting process while natural convection was developed gradually, which can increase the melting rate in the top region at the later stage of the melting process [81, 82].

Enthalpy-based numerical modelling has been used in a number of studies to investigate the heat transfer and thermal behavior of nano-enhanced PCMs. Using a 2D computational fluid dynamics (CFD) model by considering the phase change phenomenon through an enthalpy method, Sciacovelli et al. [83] analyzed the melting of a single vertical shell-andtube thermal energy storage charged with paraffin and copper nanoparticles. It was found that natural convection and the temperature of the inlet heat transfer fluid had a significant impact on the melting process of the nano-enhanced PCM. Buoyancy-driven current was observed and the melting rate increased greatly with the increase of the liquid fraction of the mixture. Ranjbar et al. [84] investigated the effect of dispersing copper nanoparticles in water on the solid-liquid phase change interface by using an enthalpy-porosity numerical modelling method. It was concluded that the heat conduction was dominant in both solid and liquid phases.

An enthalpy-porosity technique was used by Kashani et al. $[18,85]$ to track the solidliquid interface and examine the effects of the surface waviness, volume fraction of nanoparticles and wall temperature on the solidification of nano-enhanced PCMs in a vertical enclosure. Copper was used as nanoparticles and both water and n-hexadecane were used as the base fluids. It was found that the surface waviness can be used to control the solidification time of the mixture. A lower wall temperature and a higher nanoparticle volume fraction can result in a large solid fraction.

The melting of the nano-enhanced PCMs in a square cavity was studied in $[86,87]$. The SIMPLE method was used to solve the governing equations. The results showed that a higher melting rate can be achieved by using the nano-enhanced PCMs as compared to that of using the PCM base fluids. The same conclusion was also obtained by Hosseinizadeh et al. [88] 
through dispersing copper nanoparticles in RT27 from Rubitherm in a spherical container. Zhang et al. [89] examined the phase change interface of erythritol with copper nanoparticles in a spherical container. It was found that, during the heat discharging process, the phase change interface moved from the spherical shell to the ball center, and this interface moving speed increased with the decrease of the ambient temperature.

An enthalpy-based lattice Boltzmann approach was used by Jourabian et al. [90] to trace the phase change front of water embedded with copper nanoparticles in a cylindricalhorizontal annul. It was found that the temperature distribution rate of the mixture was faster than that of water, resulting in a higher melting rate.

Rao et al. [91] employed the condensed-phase optimized molecular potentials for atomistic simulation studies (COMPASS) force field to examine the heat and mass transfer mechanisms of n-nonadecane dispersed with aluminum nanoparticles. The diameters of the nanoparticles used were 1, 2, 3 and $4 \mathrm{~nm}$, respectively. It was shown that the mobility of the nano-enhanced PCMs decreased with the increase of the nanoparticle diameters.

Shaikh et al. [92] developed a theoretical model by using the Lennard-Jones potential to examine the intermolecular interactions between nanoadditives and shell wax. Three different nanoadditives, including single-walled CNTs, multi-walled CNTs and CNFs, were considered. It was found that a high molecular density and a large surface area of singlewalled CNTs can result in greater intermolecular interactions and larger latent energy of the mixture.

The effects of copper nanoparticles on the development of the solid-liquid interface and concentration profiles of nano-enhanced PCMs were numerically investigated by EI Hasadi and Khodadadi $[93,94]$. The interface was planar when dispersing copper nanoparticles with a size of $5 \mathrm{~nm}$ in water and it was developed to an unstable dendritic structure when the nanoparticle size decreased to $2 \mathrm{~nm}$ [93]. The dispersion of copper nanoparticles in 
cyclohexane showed that the movement of the solid-liquid interface was slowed downed with the increase of the volume fraction of the nanoparticles, and the decelerated movement was more obvious with the decrease of the particle size [94].

The above studies demonstrated that appropriate modelling and experimental investigation can play an essential role in helping understand the fundamental mechanisms behind the thermal conductivity enhancement, and melting and solidification characteristics of nano-enhanced PCMs. However, the interactions between the nanometer-sized materials and PCM base fluids have not been fully studied. Sophisticated models and well-designed experimental facilities are still needed to investigate the moving solid-liquid phase change front and track the movement of nanoparticles within nano-enhanced PCMs to better understand how nanometer-sized materials drive the performance enhancement of PCM base fluids.

\subsection{Application of nano-enhanced PCMs in buildings}

As nano-enhanced PCMs exhibit better thermophysical performance than PCMs, several studies have discussed the use of nano-enhanced PCMs in buildings for effective thermal management and peak load reduction, and investigated the potential energy savingsdue to the use of this new class of materials.

Kumaresan et al. [36] reported that 6-9\% energy savings in a chiller integrated with a deionized water-based thermal energy storage system can be achieved for building cooling applications and thermal management of intermittently operated electronic devices, through dispersing multi-walled carbon nanotubes. Compared to the deionized water, the solidification time of the nano-enhanced PCM was reduced by $14.0 \sim 20.1 \%$ when the volume fraction of carbon nanotubes was $0.6 \%$, depending on the surrounding bath temperature.

Guo [95] presented a study on the application of paraffin (i.e. n-octadecane) incorporating alumina nanoparticles in the building ceiling board. Based on the enthalpy-porosity 
modelling and CFD analysis, it was found that the ceiling board with the nano-enhanced PCM can save substantial amount of cooling energy in summer but the energy saving percentage was not reported in this study.

Sayyar et al. [96] and Biswas et al. [97] reported on the use of a nano-enhanced PCM with fatty acids and graphite interconnected nanosheets for energy efficient building constructions. The weight fraction of graphite considered was $8.0 \%$. The nano-enhanced PCM was incorporated into a gypsum wallboard using a sandwich structure. The numerical modelling and experimental investigation showed that the use of this enhanced gypsum wallboard can result in $79 \%$ energy savings, while still maintaining satisfied indoor thermal comfort.

Through investigating the thermal conductivity and phase change properties of alumina/water with chitosan as a dispersant, Teng [98] concluded that using appropriate fraction of alumina into water can improve the performance of ice storage air-conditioning systems. In a recent review, Al-Kayiem et al. [99] discussed the application of nanoenhanced PCMs for heating and cooling of buildings through enhancing the thermal storage capacity. Based on the thermo-physical characterization of polyethylene glycols mixed with epoxy resin and aluminum powder by using DSC measurements, Constantinescu et al. [100] concluded that this nano composite is suitable for building applications due to its large latent heat, appropriate phase change temperature and good stability.

Parameshwaran et al. $[38,101]$ investigated the thermal properties of ester embedded with silver nanoparticles and silver-titania hybrid nano-composite for thermal energy storage applications in buildings. Compared to the pure PCM, the freezing time and melting time of the mixture were reduced by 30.8 and $11.3 \%$ respectively, when the weight fraction of silver particles was 5.0\% [38]. The use of silver-titania hybrid nano-composite with the mass fraction ranging from 0.1 to $1.5 \%$ showed that the thermal conductivity of the nano-enhanced 
PCM was improved by $10-52 \%$ and energy savings can be obtained due to the reduction of the freezing time [101]. Parameshwaran and Kalaiselvam [102] experimentally investigated the performance of a chilled water based variable air volume air conditioning system by integrating a PCM thermal storage system with silver nanoparticles. The results showed that 36-58 and 24-51\% on-peak and daily average energy savings can be achieved by using this air conditioning system with the nano-enhanced PCM, respectively.

The heat transfer characteristics in terms of the transient temperature variation, moving solid-liquid interface position, and solidification and melting rates, were analytically and experimentally investigated by Kalaiselvam et al. [103] for cooling applications in buildings. The results showed that, compared to the PCM base fluid, the solidification time for $60 \% \mathrm{n}$ tetradecane and $40 \%$ n-hexadecane PCM dispersed with the aluminum and alumina nanoparticles with a volume fraction of $7.0 \%$ can reduce by $12.97 \%$ and $4.97 \%$, respectively. Colella et al. [104] numerically investigated the use of a paraffin-graphite composite with a $15 \%$ graphite volume fraction to enhance a shell-and-tube energy storage unit with water as the heat transfer fluid for district heating systems. Compared to traditional water storage systems for district heating, the energy storage unit with the nano-enhanced PCM can provide higher energy storage densities.

Although nano-enhanced PCMs have been extensively studied, only a limited number of recent studies focused on the use of this new class of materials in buildings. Detailed studies on investigating thermodynamic characteristics and performance enhancement mechanisms of buildings by using nano-enhanced PCMs are still missing. There are only a very limited number of studies focusing on the integration of nano-enhanced PCMs with building HVAC systems. Again, it is worthwhile to note that special care should be taken when using this new class of materials in buildings due to possible negative impacts of nanometer-size materials 
on human beings and environment. The major nano-enhanced PCMs studied in the literature reviewed and the key findings are summarized in Table 2.

\section{Case study of using nano-enhanced PCMs in a building ceiling ventilation system}

\subsection{Description of the building and system}

The building concerned in this case study is a Solar Decathlon (SD) house, as illustrated in Fig. 2. This SD house consists of a main bedroom, a study/guest bedroom, and an open plan living room connected with the dining room and kitchen. In this house, a pitched ceiling was designed for the living room in order to optimize the air movement while the ceilings of the other spaces remain horizontal (see Fig. 2b).

A PCM ceiling ventilation system integrated with air-based solar photovoltaic thermal (PVT) collectors, as shown in Fig. 3, was designed and assumed to be implemented in this house [105]. The two PCM layers with an air channel between them were assumed to be attached onto the pitched ceiling to increase its local thermal mass, and at the same time, to serve as a thermal energy storage unit to temporally store the low grade thermal energy collected from the PVT collectors and use it later for space heating in winter or space cooling in summer using PVT night-time sky radiative cooling. The north side of the whole roof including the pitched ceiling was assumed to be covered with the PVT collectors.

This system can operate with different modes on the basis of the weather conditions and indoor heating/cooling demand through controlling the ON/OFF of the isolation valves (V1V5) [105]. For instance, in the winter heating case, during the daytime, the solar heated hot air from the PVT collectors can be used to charge the PCM layers and then discharged to the ambient air by switching on the isolation valves 2 and 5, or then used for space heating by switching on the isolation valves 2 and 4. During the night-time, the thermal energy stored in the PCM layers can be used to heat the circulation air from the building for space heating by 
switching on the isolation valves 3 and 4. More details on the operation modes of this system can be found in Ref. [105].

\subsection{Nano-enhanced PCM considered}

In this study, a commercial PCM named as RT24 from Rubitherm Co. Ltd was considered as the PCM base fluid. Copper nanoparticles with a volume fraction of $10 \%$ were assumed to be evenly dispersed into the PCM base fluid to increase its thermal conductivity. The average diameter and nano-layer thickness of the copper particles used were $6 \mathrm{~nm}$ and 2 $\mathrm{nm}$, respectively [106]. The nano-layer thermal conductivity was considered as 100 times of the thermal conductivity of the PCM base fluid [106]. The thermo-physical properties of the PCM RT24 and copper nanoparticles are summarized in Table 3 [87, 107].

The thermal conductivity of the nano-enhanced PCM was determined by the modified Maxwell equation, as expressed in Equation (2), in which the equivalent thermal conductivity of the equivalent nanoparticles $\left(k_{e p}\right)$ was determined by Equation (3) [106].

$$
\begin{gathered}
k_{N E P C M}=\frac{k_{e p}+2 k_{P C M}+2\left(k_{e p}-k_{P C M}\right)(1+\beta)^{3} \phi}{k_{e p}+2 k_{P C M}-\left(k_{e p}-k_{P C M}\right)(1+\beta)^{3} \phi} k_{P C M} \\
k_{e p}=\frac{\left[2(1-\gamma)+(1+\beta)^{3}(1+2 \gamma)\right] \gamma}{-(1-\gamma)+(1+\beta)^{3}(1+2 \gamma)} k_{n p}
\end{gathered}
$$

where, $k$ is the thermal conductivity, $\phi$ is the volume fraction of the copper particles dispersed in the PCM base fluid, $\beta$ is the ratio of the nano-layer thickness to the nanoparticle radius, $\gamma$ is the ratio of nano-layer thermal conductivity to the nanoparticle thermal conductivity, and subscripts NEPCM, PCM, np and ep indicate nano-enhanced PCM, PCM, nanoparticles and equivalent nanoparticles, respectively.

The density, specific heat and heat of fusion of the nano-enhanced PCM were determined by Equations (4), (5) and (6) respectively, based on the simple mixture theory [74, 94]. 


$$
\begin{gathered}
\rho_{N E P C M}=(1-\phi) \rho_{P C M}+\phi \rho_{n p} \\
\left(\rho C_{p}\right)_{N E P C M}=(1-\phi)\left(\rho C_{p}\right)_{P C M}+\phi\left(\rho C_{p}\right)_{n p} \\
(\rho L)_{N E P C M}=(1-\phi)(\rho L)_{P C M}
\end{gathered}
$$

where, $\rho$ is the density, $C_{p}$ is the specific heat, and $L$ is the latent heat.

\subsection{Setup of the tests}

In this study, the simulation of the building and system was performed based on the platform developed in our previous study using TRNSYS [105]. The building model was developed by using Google SketchUp and TRNBuild, and then imported into Type 56 MultiZone building component in TRNSYS studio. The PVT model and PCM model used were briefly described in Appendix.

The TMY weather data of Sydney was used as the test conditions to evaluate the performance of the PCM ceiling ventilation system. Fig. 4 illustrates the weather data, including the ambient air temperature, sky temperature, and total solar radiation over the four winter consecutive days used in this study. To eliminate the influence of the initial conditions on the system performance analysis, only the results of the last three days are presented below.

During the tests, the initial temperature of the PCM (and nano-enhanced PCM) was assumed to be $15^{\circ} \mathrm{C}$ and the thermal energy stored in the PCM layers was set to be zero. The thickness of each PCM layer used was $15 \mathrm{~mm}$. The total areas of the PVT collectors and each PCM layer used were $40.0 \mathrm{~m}^{2}$ and $14.0 \mathrm{~m}^{2}$, respectively.

In the test, during the daytime, the PCM was charged by the heated hot air from the PVT collectors if the PVT outlet air temperature was higher than the equivalent PCM temperature defined in Equation (7). The heat stored in the PCM was released during the night-time when the indoor temperature was lower than the lower limit of the indoor thermal comfort range specified in NatHERS [108]. The discharging operation mode lasted until either the thermal 
heat stored in the PCM was fully discharged or the outlet air temperature from the PVT collectors was suitable for heat charging. Due to the different fan sizes of the PVT collectors and PCM storage unit, different air flow rates were used in this study. The air flow rate used for the PVT collectors was $500 \mathrm{~kg} / \mathrm{h}$ and the air flow rate used for the PCM discharging was $1500 \mathrm{~kg} / \mathrm{h}$.

$$
\bar{T}=T_{s}+\alpha \times\left(T_{l}-T_{s}\right)
$$

where, $\alpha$ is the ratio of the heat stored in the PCM to the total design thermal storage capacity of the PCM layers, and $T_{l}$ and $T_{s}$ indicate the upper melting temperate and lower melting temperature of the PCM.

\subsection{Test results}

Fig. 5 shows the percentages of the thermal energy stored in the pure PCM layers and nano-enhanced PCM layers under the three winter test days. It can be found clearly that the thermal energy stored in the PCM layers varied with the variation of the weather conditions. The maximum percentages of the thermal energy stored in the nano-enhanced PCM and pure PCM were $86.5 \%$ and $80.4 \%$ of their design thermal storage capacities, respectively. It can also be observed that the slope of the curve by using the nano-enhanced PCM was larger than that of using the pure PCM, demonstrating that the nano-enhanced PCM has higher melting and solidification rates, compared to that of the pure PCM. The rapid melting and solidification rates can increase the amount of the heat charged in or discharged from the thermal energy storage per unit time.

Table 4 summarizes the total heat charged in and discharged from the pure PCM layers and nano-enhanced PCM layers under the three winter test days. It is shown that $22.03 \mathrm{kWh}$ and $23.85 \mathrm{kWh}$ heat were charged in the pure PCM layers and nano-enhanced PCM layers respectively, under the three test days. Compared to the use of the pure PCM, 8.3\% more heat was charged in the nano-enhanced PCM layers. The total heat discharged from the pure PCM 
layers and nano-enhanced PCM layers were 8.52 and $10.66 \mathrm{kWh}$, respectively. The results from Table 4 also indicated that 13.51 and $13.19 \mathrm{kWh}$ net heat energy were charged in the pure PCM layers and nano-enhanced PCM layers under the three test days, respectively.

Fig. 6 illustrates the outlet air temperatures from the PVT collectors and PCM (and nanoenhanced PCM) layers, and the ambient air temperature under the three test days. It can be found that the temperature of the ambient air after flowing through the PVT collectors was increased significantly. The maximum PVT outlet air temperature under the three test days was $39.39^{\circ} \mathrm{C}$. When the heated hot air from the PVT collectors flowed through the PCM layers, the heat in the air was charged into the PCM layers. It is shown that the temperature of the outlet air from the pure PCM layers was slightly higher than that from the nano-enhanced PCM layers during the winter daytime period, while it was slightly lower than that from the nano-enhanced PCM layers during the winter night-time period. This further demonstrates that nano-enhanced PCM has faster melting and solidification rates, as compared to that of the pure PCM.

The results from this case study showed that the dispersion of the copper nanoparticles in the PCM base fluid of RT24 can increase its melting and solidification rates due to the enhanced thermal conductivity. However, to maximize the benefits by using the nanoenhanced PCM in this system, a systematic methodology should be developed to optimize the major design variables, such as the amount and type of the PCM used, the type of nanoparticles used and their volume fraction in the PCM base fluid, PVT air flow rate, PCM discharging air flow rate, etc.

\section{Conclusions and discussions}

This paper provided a generic framework for the appropriate use of nano-enhanced phase change materials (PCMs) in buildings. An overview on major recent development and application of nano-enhanced PCMs as thermal energy storage media was provided and the 
major results were summarized in Table 2. A case study based on a PCM ceiling ventilation system with air-based photovoltaic thermal (PVT) collectors was used to evaluate the potential benefits by using nano-enhanced PCMs in this system. Some conclusive remarks and recommendations for future work in this direction are as follows.

- Most existing studies have demonstrated that the dispersion of high thermal conductive nanometer-sized materials into the PCM base fluid can enhance the thermal conductivity and increase the melting and solidification rates of the mixture.

- Nano-enhanced PCMs have been extensively studied during the last ten years, in particular during the last three years. However, only a very limited number of studies focused on the use of this new class of materials in buildings, and building HVAC systems.

- Most studies did not address the potential negative impacts of nanometer-sized materials on human beings and environment. A detailed risk assessment and necessary protection actions should be considered when using nano-enhanced PCMs in buildings.

- The studies focusing on the investigation of the energy transport mechanisms of nanoenhanced PCMs are far from sufficient. Significant work is still needed to explore the effects of a wide range of variables and factors on the thermal conductivity enhancement of PCMs and understand the intermolecular interaction behind the thermal conductivity enhancement. These fundamental mechanisms can be better examined by a combination of both molecular scale and macroscopic scale simulations.

- The case study based on a ceiling ventilation system showed that $8.3 \%$ more heat was charged in and $25.1 \%$ more heat was discharged from the nano-enhanced PCM under the three winter test days, compared to the pure PCM. This demonstrates that nano- 
enhanced PCMs have higher melting and solidification rates and could be able to address one of the key barriers (i.e. low thermal conductivity) towards the wide adoption of PCMs in buildings.

\section{Appendix}

\section{PVT modelling}

The PVT model used was a dynamic model developed in a previous study [109]. The key governing equations used are presented in Equations (A.1)-(A.3). By using this model, the PVT outlet air temperature, PV panel temperature, electrical power generation and thermal efficiency can be easily determined.

$$
\begin{aligned}
& \dot{m}_{f} c_{p, f} \frac{d T_{f}}{d x}=W_{P V T}\left(q_{p-f}-q_{f-b}\right) \\
& m_{p} c_{p, p} \frac{d T_{p}}{d t}=\left(1-\rho_{r e f}\right) \cdot I A M \cdot\left(1-\eta_{p}\right) \cdot A_{p} \cdot G t-Q_{L}-Q_{p-f}-Q_{p-b} \\
& m_{b} c_{p, b} \frac{d T_{b}}{d t}=Q_{p-b}+Q_{f-b}-Q_{b-P C M}
\end{aligned}
$$

where, $\dot{m}$ is the air mass flow rate, $m$ is the mass, $A$ is the area of the PVT collectors, $T$ is the temperature, $G t$ is the total horizontal solar irradiation, $W$ is the width of the PVT collectors, $\rho_{\text {ref }}$ is the reflectance of the PV surface, IAM is the incidence angle modifier, $\eta_{P}$ is the electric efficiency of the PVT collectors, $q$ is the heat transfer rate per square meter, $Q$ is the heat transfer rate, $c_{p}$ is the specific heat capacity, subscripts $f, p, b$ and $L$ indicates the working fluid, the PV panels, the insulation layer and heat loss, respectively, and subscripts $p-f, p-b, f-b$ and $b-P C M$ indicate the heat transfer direction from the PV panels to the fluid, from the PV panels to the insulation layer, from the fluid to the back insulation and from the insulation layer to the PCM layer, respectively.

PCM modelling 
The PCM model used was a lumped enthalpy model developed in our previous study [105].

The key governing equations used are shown in Equations (A.4)-(A.6).

$$
\begin{aligned}
& m_{\text {air }} c_{p, a i r} \frac{d T_{\text {air }}}{d t}=-Q_{\text {bottom }, P C M 1}-Q_{\text {top }, P C M 2}-\dot{m}_{\text {air }} c_{p, a i r}\left(T_{\text {air }, \text { uut }}-T_{\text {air }, \text { in }}\right) \\
& m_{P C M 1} \frac{d h_{P C M 1}}{d t}=Q_{\text {bottom }, P C M 1}+Q_{t o p, P C M 1} \\
& m_{P C M 2} \frac{d h_{P C M 2}}{d t}=Q_{\text {bottom } P C M 2}+Q_{t o p, P C M 2}
\end{aligned}
$$

where, $m$ is the mass, $\dot{m}$ is the mass flow rate, $T$ is the temperature, $c_{p}$ is the specific heat capacity, $Q$ is the heat transfer rate, $h$ is the enthalpy, subscripts $P C M 1$ and $P C M 2$ indicate the PCM layer 1 and the PCM layer 2 respectively, subscripts top and bottom indicate the top and bottom surfaces of each PCM layer respectively, subscripts in and out indicate the air inlet and outlet of the PCM control volume respectively.

\section{References}

1. Butler D. Architecture: Architects of a low-energy future. Nature 2008; 452:520-3.

2. Hughes BR, Chaudhry HN, Ghani SA. A review of sustainable cooling technologies in buildings. Renewable and Sustainable Energy Reviews 2011;15:3112-20.

3. Rosiek S, Batlles FJ. Renewable energy solutions for building cooling, heating and power system installed in an institutional building: Case study in southern Spain. Renewable and Sustainable Energy Reviews 2013;26:147-68.

4. Ma Z, Wang S. Enhancing the performance of large primary-secondary chilled water systems by using bypass check valve. Energy 2011;36:268-76.

5. Niu XF, Xiao F, Ma Z. Investigation on capacity matching in liquid desiccant and heat pump hybrid air-conditioning systems. International Journal of Refrigeration 2012;35:160-70.

6. Zhu N, Ma Z, Wang S. Dynamic characteristics and energy performance of buildings using phase change materials: A review. Energy Conversion and Management 2009;50:3169-81.

7. Memon SA. Phase change materials integrated in building walls: A state of the art review. Renewable and Sustainable Energy Reviews 2014;31:870-906.

8. Waqas A, Ud Din Z. Phase change material (PCM) storage for free cooling of buildings-A review. Renewable and Sustainable Energy Reviews 2013;18:607-25. 
9. Zhu N, Wang S, Xu, X, Ma Z. A simplified dynamic model of building structures integrated with shaped-stabilized phase change materials. International Journal of Thermal Sciences 2010;49:1722-31.

10. Salunkhe PB, Shembekar PS. A review on effect of phase change material encapsulation on the thermal performance of a system. Renewable and Sustainable Energy Reviews 2012;16:5603-16.

11. Mondal S. Phase change materials for smart textiles - An overview. Applied Thermal Engineering 2008;28:1536-50.

12. Atwood G. Phase-change materials for electronic memories. Science 2008;321:210-1.

13. Sharma A, Tyagi VV, Chen CR, Buddhi D. Review on thermal energy storage with phase change materials and applications. Renewable and Sustainable Energy Reviews 2009;13:318-45.

14. Kenfack F,Bauer M. Innovative phase change material (PCM) for heat storage for industrial applications. Energy Procedia 2014;46:310-16.

15. Lochan A, Arif M. Phase change materials and potential applications. International Journal of Applied Engineering Research 2013;8:2115-20.

16. Ji H, Sellan DP, Pettes MT, Kong X, Ji J, Shi J, Ruoff R. Enhanced thermal conductivity of phase change materials with ultrathin-graphite foams for thermal energy storage. Energy \& Environmental Science 2013;7:1185-92.

17. Khodadadi JM, Fan L, Babaei H. Thermal conductivity enhancement of nanostructurebased colloidal suspensions utilized as phase change materials for thermal energy storage: A review. Renewable and Sustainable Energy Reviews 2013;24:418-44.

18. Kashani S, Ranjbar AA, Madani MM, Mastiani M, Jalaly H. Numerical study of solidification of a nano-enhanced phase change material (NEPCM) in a thermal storage system. Journal of Applied Mechanisc and Technical Physics 2013;54:702-12.

19. Wu S, Wang H, Xiao S, Zhu DS. An investigation of melting/freezing characteristics of nanoparticle-enhanced phase change materials. Journal of Thermal Analysis and Calorimetry 2013;110:1127-31.

20. Sharifi N, Wang S, Bergman TL, Faghri A. Heat pipe-assisted melting of a phase change material. International Journal of Heat and Mass Transfer 2012;55:3458-69.

21. Delgado M, Lázaro A, Mazo J, Zalba B. Review on phase change material emulsions and microencapsulated phase change material slurries: Materials, heat transfer studies and applications. Renewable and Sustainable Energy Reviews 2012;16:253-73.

22. Shaikh S, Lafdi K. Effect of multiple phase change materials (PCMs) slab configurations on thermal energy storage. Energy Conversion and Management 2006;47:2103-17.

23. Elgafy A, Lafdi K. Effect of carbon nanofiber additives on thermal behavior of phase change materials. Carbon 2005;43:3067-74.

24. Peippo K, Kauranen P, Lund PD. A multicomponent PCM wall optimized for passive solar heating. Energy and Buildings 1991;17:259-70.

25. Cabeza LF, Castell A, Barreneche C, de Gracia A, Fernández AI. Materials used as PCM in thermal energy storage in buildings: A review. Renewable and Sustainable Energy Reviews 2011;15:1675-95. 
26. Tyagi VV, Buddhi D. PCM thermal storage in buildings: A state of art. Renewable and Sustainable Energy Reviews 2007;11:1146-66.

27. Pielichowska K, Pielichowski K. Phase change materials for thermal energy storage. Progress in Materials Science 2014;65:67-123.

28. Teng TP, Yu CC. Characteristics of phase-change materials containing oxide nanoadditives for thermal storage. Nanoscale Research Letters 2012;7:611-21.

29. Oya T, Nomura T, Tsubota M, Okinaka N, Akiyama T. Thermal conductivity enhancement of erythritol as PCM by using graphite and nickel particles. Applied Thermal Engineering 2013;61:825-28.

30. Hwang Y, Lee JK, Lee JK, Jeong YM, Cheong S, Ahn YC, Kim SH. Production and dispersion stability of nanoparticles in nanofluids. Powder Technology 2008;186:14553.

31. Yu X, Xie H A review on nanofluids: Preparation, stability mechanisms, and applications. Journal of Nanomaterials 2012;435873:1-17.

32. Wang XQ, Mujumdar AS. Heat transfer characteristics of nanofluids: a review. International Journal of Thermal Sciences 2007;46:1-19.

33. He Q, Wang S, Tong M, Liu Y. Experimental study on thermophysical properties of nanofluids as phase-change material (PCM) in low temperature cool storage. Energy Conversion and Management 2012;64:199-205.

34. Wu S, Zhu D, Zhang X, Huang J. Preparation and Melting/Freezing Characteristics of $\mathrm{Cu}$ /Paraffin Nanofluid as Phase-Change Material (PCM). Energy Fuels 2010;24:18948.

35. Harikrishnan S, Kalaiselvam S. Preparation and thermal characteristics of $\mathrm{CuO}-$ oleic acid nanofluids as a phase change material. Thermochimica Acta 2012;533:46-55.

36. Kumaresan V, Chandrasekaran P, Nanda M, Maini AK, Velraj R. Role of PCM based nanofluids for energy efficient cool thermal storage system. International Journal of Refrigeration 2013;36:1641-7.

37. Fuensanta M, Paiphansiri U, Romero-Sánchez MD, Guillem C, López-Buendía AM, Landfester K. Thermal properties of a novel nanoencapsulated phase change material for thermal energy storage. Thermochimica Acta 2013;565:95-101.

38. Parameshwaran R, Jayavel R, Kalaiselvam S. Study on thermal properties of organic ester phase-change material embedded with silver nanoparticles. Journal of Thermal Analysis and Calorimetry 2013;114:845-58.

39. Zeng Y, Fan LW, Xiao YQ, Yu ZT, Cen KF. An experimental investigation of melting of nanoparticle-enhanced phase change materials (NePCMs) in a bottom-heated vertical cylindrical cavity. International Journal of Heat and Mass Transfer 2013;66:111-7.

40. Hong Y, Ding S, Wu W, Hu J, Voevodin AA, Gschwender L, Snyder E, Chow L, Su M. Enhancing heat capacity of colloidal suspension using nanoscale encapsulated phase-change materials for heat transfer. ACS Applied Materials \& Interfaces 2010;2:1685-91.

41. Ho CJ, Gao JY. Preparation and thermophysical properties of nanoparticle-in-paraffin emulsion as phase change material International Communications in Heat and Mass Transfer 2009;36:467-70. 
42. Li Y, Shi C, Liu J, Liu E, Saho J, Chen Z, Dorantes-Gonzalez DJ, Hu X. Improving the accuracy of the transient plane source method by correcting probe heat capacity and resistance influences. Meas. Sci. Technol. 2014;25(015006):1-7.

43. Thermal Conductivity Instruments. http://www.ctherm.com/products/tci_thermal_conductivity. Accessed 30 April 2014.

44. Goh WF, Khan SA, Yoon TL. A molecular dynamics study of the thermodynamic properties of barium zirconate. Modelling Simul. Mater. Sci. Eng. 2013;21(045001):111.

45. Haile JM. Molecular dynamic simulation: Elementary methods. John Wiley \& Sons, New York, 1997.

46. Rapaport DC. The art of molecular dynamics simulation (second edition). Cambridge University Press, United Kingdom, 2004.

47. Rao Z, Wang S, Peng F. Self diffusion of the nano-encapsulated phase change materials: A molecular dynamics study. Applied Energy 2012;100:303-8.

48. Babaei H, Keblinski P, Khodadadi JM. Improvement in thermal conductivity of paraffin by adding high aspect-ratio carbon-based nano-fillers. Physics Letters A 2013;377:1358-61.

49. Sarkar S, Selvam RP. Molecular dynamics simulation of effective thermal conductivity and study of enhanced thermal transport mechanism in nanofluids. Journal of Applied Physics 2007;102(074302):1-7.

50. Li L, Zhang Y, Ma H, Yang M. An investigation of molecular layering at the liquidsolid interface in nanofluids by molecular dynamics simulation. Physics Letters A 2008;372:4541-4.

51. Nedjar B. An enthalpy-based finite element method for nonlinear heat problems involving phase change. Computers and Structures 2002;80:9-21.

52. Minkowycz WJ, Sparrow EM. Advances in numerical heat transfer (Volume 1). Taylor \& Francis, New York, 1997.

53. Banki R, Hoteit H, Firoozabadi A. Mathematical formulation and numerical modeling of wax deposition in pipelines from enthalpy-porosity approach and irreversible thermodynamics. International Journal of Heat and Mass Transfer 2008;51:3387-98.

54. Zhao W, Elmozughi AF, Oztekin A, Neti S. Heat transfer analysis of encapsulated phase change material for thermal energy storage. International Journal of Heat and Mass Transfer 2013;63:323-35.

55. Bhattacharya M, Basak T, Ayappa KG. A fixed-grid finite element based enthalpy formulation for generalized phase change problems: role of superficial mushy region. International Journal of Heat and Mass Transfer 2002;45:4881-98.

56. Soares N, Costa JJ, Gaspar AR, Santos P. Review of passive PCM latent heat thermal energy storage systems towards buildings' energy efficiency. Energy and Buildings 2013;59:82-103.

57. Fan L, Khodadadi JM. Thermal conductivity enhancement of phase change materials for thermal energy storage: A review. Renewable and Sustainable Energy Reviews 2011;15:24-46. 
58. Paksoy H, Sahan N. Thermally enhanced paraffin for solar applications. Energy Procedia 2012;30:350-52.

59. Sheikh MH, Sharif MAR. Methods for separation of copper oxide nanoparticles from colloidal suspension in Dodecane. Journal of Nanotechnology in Engineering and Medicine 2014;5(011002):1-9.

60. Li M. A nano-graphite/paraffin phase change material with high thermal conductivity. Applied Energy 2013;106:25-30.

61. Ehid R, Weinstein RD, Fleischer AS. The shape stabilization of paraffin phase change material to reduce graphite nanofiber settling during the phase change process. Energy Conversion and Management 2012;57:60-7.

62. Fan, LW, Fang X, Wang X, Zeng Y, Xiao YQ, Yu ZT, Xu X, Hu YC, Cen KF., Effects of various carbon nanofillers on the thermal conductivity and energy storage properties of paraffin-based nanocomposite phase change materials. Applied Energy 2013;110:163-72.

63. Yu ZT, Fang X, Fan LW, Wang X, Xiao YQ, Zeng Y, Xu X, Hu YC, Cen KF. Increased thermal conductivity of liquid paraffin-based suspensions in the presence of carbon nano-additives of various sizes and shapes. Carbon 2013;53:277-85.

64. Shi JN, Ger MD, Liu YM, Fan YC, Wen NT, Lin CK, Pu NW. Improving the thermal conductivity and shape-stabilization of phase change materials using nanographite additives. Carbon 2013;51:365-72.

65. Warzoha RJ, Weigand RM, Fleischer AS. Temperature-dependent thermal properties of a paraffin phase change material embedded with herringbone style graphite nanofibers. Applied Energy 2015;137:716-25.

66. Cui Y, Liu C, Hu S, Yu X. The experimental exploration of carbon nanofiber and carbon nanotube additives on thermal behavior of phase change materials. Solar Energy Materials \& Solar Cells 2011;95:1208-12.

67. Harikrishnan S, Magesh S, Kalaiselvam S. Preparation and thermal energy storage behaviour of stearic acid- $\mathrm{TiO}_{2}$ nanofluids as a phase change material for solar heating systems. Thermochimica Acta 2013;565:137-45.

68. Song Q, Li Y, Xing J, Hu JY, Marcus Y. Thermal stability of composite phase change material microcapsules incorporated with silver nano-particles. Polymer 2007;48:3317-23.

69. Zeng JL, Sun LX, Xu F, Tan ZC, Zhang ZH, Zhang J, Zhang T. Study of a PCM based energ storage system containing Ag nanoparticles. Journal of Thermal Analysis and Calorimetry 2007;87:369-73.

70. Cai Y, Ke H, Dong J, Wei Q, Lin J, Zhao Y, Song L, Hu Y, Huang F, Gao W, Fong H. Effects of nano- $\mathrm{SiO}_{2}$ on morphology, thermal energy storage, thermal stability, and combustion properties of electrospun lauric acid/PET ultrafine composite fibers as form-stable phase change materials. Applied Energy 2011;88:2106-12.

71. Wu S, Zhu D, Li X, Li H, Lei J. Thermal energy storage behavior of $\mathrm{Al}_{2} \mathrm{O}_{3}-\mathrm{H}_{2} \mathrm{O}$ nanofluids. Thermochimica Acta 2009;483:73-7.

72. Mo S, Chen Y, Yang J, Luo X. Experimental study on solidification behavior of carbon nanotube nanofluid. Advanced Materials Research 2011;171-172:333-6. 
73. Jesumathy S, Udayakumar M, Suresh S. Experimental study of enhanced heat transfer by addition of $\mathrm{CuO}$ nanoparticle. Heat Mass Transfer 2012;48:965-78.

74. Fan L, Khodadadi JM. A theoretical and experimental investigation of unidirectional freezing of nanoparticle-enhanced phase change materials. Journal of Heat TranserTransactions of the ASME 2012;134(092301):1-9.

75. Fan L, Khodadadi JM. An experimental investigation of enhanced thermal conductivity and expedited unidirectional freezing of cyclohexane-based nanoparticle suspensions utilized as nano-enhanced phase change materials (NePCM). International Journal of Thermal Sciences 2012;62:120-26.

76. Tasnim SH, Hossain R, Mahmud S, Dutta A. Convection effect on the melting process of nano-PCM inside porous enclosure. International Journal of Heat and Mass Transfer 2015;85:206-20.

77. Hossain R, Mahmud S, Dutta A, Pop I. Energy storage system based on nanoparticleenhanced phase change material inside porous medium. International Journal of Thermal Sciences 2015;91:49-58.

78. Weinstein RD, Kopec TC, Fleischer AS, D'Addio E, Bessel CA. The experimental exploration of embedding phase change materials with graphite nanofibers for the thermal management of electronics. Journal of Heat Transer-Transactions of the ASME 2008;130(0424054):1-8.

79. Sanusi O, Warzoha R, Fleischer AS. Energy storage and solidification of paraffin phase change material embedded with graphite nanofibers. International Journal of Heat and Mass Transfer 2011;54:4429-36.

80. Dhaidan NS, Khodadadi JM, Al-Hattab TA, Al-Mashat SM. Experimental and numerical investigation of melting of phase change material/nanoparticle suspensions in a square container subjected to a constant heat flux. International Journal of Heat and Mass Transfer 2013;66:672-83.

81. Dhaidan NS, Khodadadi JM, Al-Hattab TA, Al-Mashat SM. Experimental and numerical study of constrained melting of n-octadecane with $\mathrm{CuO}$ nanoparticle dispersions in a horizontal cylindrical capsule subjected to a constant heat flux. International Journal of Heat and Mass Transfer 2013;67:523-34.

82. Dhaidan NS, Khodadadi JM, Al-Hattab TA, Al-Mashat SM. Experimental and numerical investigation of melting of NePCM inside an annular container under a constant heat flux including the effect of eccentricity. International Journal of Heat and Mass Transfer 2013;67:455-68.

83. Sciacovelli A, Colella F, Verda V. Melting of PCM in a thermal energy storage unit: Numerical investigation and effect of nanoparticle enhancement. International Journal of Energy Research 2013;37:1610-23.

84. Ranjbar AA, Kashani S, Hosseinizadeh SF, Ghanbarpour M. Numerical heat transfer studies of a latent heat storage system containing nano-enhanced phase change materila. Thermal Science 2011;15:169-81.

85. Kashani S, Ranjbar AA, Abdollahzadeh M, Sebti S. Solidification of nano-enhanced phase change material (NEPCM) in a wavy cavity. Heat Mass Transer 2012;48:115566. 
86. Sebti SS, Mastiani M, Mirzaei H, Dadvand A, Kashani S, Hosseini SA. Numerical study of the melting of nano-enhanced phase change material in a square cavity. Journal of Zhejiang University-Science A 2013;14:307-16.

87. Khodadadi JM, Hosseinizadeh SF. Nanoparticle-enhanced phase change materials (NEPCM) with great potential for improved thermal energy storage. International Communications in Heat and Mass Transfer 2007;34:534-43.

88. Hosseinizadeh SF, Rabienataj Darzi AA, Tan FL. Numerical investigations of unconstrained melting of nano-enhanced phase change material (NEPCM) inside a spherical container. International Journal of Thermal Sciences 2012;51:77-83.

89. Zhang X, Chen X, Han Z, Xu W. Study on phase change interface for erythritol with nano-copper in spherical container during heat transport. International Journal of Heat and Mass Transfer 2016;92:490-96.

90. Jourabian M, Farhadi M, Rabienataj Darzi AA. Outward melting of ice enhanced by $\mathrm{Cu}$ nanoparticles inside cylindrical horizontal annulus: Lattice Boltzmann approach. Applied Mathematical Modelling 2013;37:8813-25.

91. Rao Z, Wang S, Peng F. Molecular dynamics simulations of nano-encapsulated and nanoparticle-enhanced thermal energy storage phase change materials. International Journal of Heat and Mass Transfer 2013;66:575-84.

92. Shaikh S, Lafdi K, Hallinan K. Carbon nanoadditives to enhance latent energy storage of phase change materials. Journal of Applied Physics 2008;103( 094302):1-6.

93. El Hasadi YMF, Khodadadi JM. Numerical simulation of the effect of the size of suspensions on the solidification process of nanoparticle-enhanced phase change materials. Journal of Heat Transer-Transactions of the ASME 2013;135(052901):1-11.

94. El Hasadi YMF, Khodadadi JM. One-dimensional Stefan problem formulation for solidification of nanostructure-enhanced phase change materials (NePCM). International Journal of Heat and Mass Transfer 2013;67:202-13.

95. Guo C. Application study of nanoparticle-enhanced phase change material in ceiling board. Advanced Materials Research 2010;150-151:723-6.

96. Sayyar M, Weerasiri RR, Soroushian P, Lu J. Experimental and numerical study of shape-stable phase-change nanocomposite toward energy-efficient building constructions. Energy and Buildings 2014;75:249-55.

97. Biswas K, Lu J, Soroushian P, Shrestha S. Combined experimental and numerical evaluation of a prototype nano-PCM enhanced wallboard. Applied Energy 2014;131: 517-29.

98. Teng TP. Thermal conductivity and phase-change properties of aqueous alumina nanofluid. Energy Conversion and Management 2013;67:369-75.

99. Al-Kayiem HH, Lin SC, Lukmon A. Review on nanomaterials for thermal energy storage technologies. Nanoscience \& Nanotechnology-Asia 2013:3:60-71.

100. Constantinescu M, Dumitrache L, Constantinescu D, Anghel EM, Popa VT, Stoica A, Olteanu M. Latent heat nano composite building materials. European Polymer Journal 2010;46:2247-54.

101. Parameshwaran R, Deepak K, Saravanan R, Kalaiselvam S. Preparation, thermal and rheological properties of hybrid nanocomposite phase change material for thermal energy storage. Applied Energy 2014;115:320-30. 
102. Parameshwaran R, Kalaiselvam S. Energy conservative air conditioning system using silver nano-based PCM thermal storage for modern buildings. Energy and Buildings 2014;69:202-12.

103. Kalaiselvam S, Parameshwaran R, Harikrishnan S. Analytical and experimental investigations of nanoparticles embedded phase change materials for cooling application in modern buildings. Renewable Energy 2012;39:375-87.

104. Colella F, Sciacovelli A, Verda V. Numerical analysis of a medium scale latent energy storage unit for district heating systems. Energy 2012;45:397-406.

105. Lin W, Ma Z, Sohel MI, Cooper P. Development and evaluation of a ceiling ventilation system enhanced by solar photovoltaic thermal collectors and phase change materials. Energy Conversion and Management 2014;88:218-30.

106. Yu W, Choi SUS. The role of interfacial layers in the enhanced thermal conductivity of nanofluids: A renovated Maxwell model. Journal of Nanoparticle Research 2003;5: $167-71$.

107. Rubitherm. http://www.rubitherm.de/english/pages/02a_latent_heat_pcms.htm. Accessed 10 March 2014.

108. NaTHERS, www.nathers.gov. au. Accessed 3 January 2014.

109. Sohel MI, Ma Z, Cooper P, Adams J, Scott R. A dynamic model for air-based photovoltaic thermal systems working under real operating conditions. Applied Energy 2014;132:216-25.

Table 1 Summary of major techniques to characterize thermo-physical properties of nanoenhanced PCMs [7, 33, 37-41]

\begin{tabular}{|c|c|c|}
\hline No & Technique & Function \\
\hline 1 & $\begin{array}{l}\text { Differential scanning } \\
\text { calorimeter (DSC) }\end{array}$ & $\begin{array}{l}\text { Determine the phase change temperature and heat of } \\
\text { fusion of sampling materials }\end{array}$ \\
\hline 2 & $\begin{array}{l}\text { Thermal conductivity } \\
\text { analyzer (TCA) }\end{array}$ & $\begin{array}{l}\text { Measure the thermal conductivity of sampling } \\
\text { materials }\end{array}$ \\
\hline 3 & $\begin{array}{l}\text { Scanning electron microscope } \\
(\mathrm{SEM})\end{array}$ & Image the morphology of nanometer-sized materials \\
\hline 4 & $\begin{array}{l}\text { Transmission electron } \\
\text { microscope (TEM) }\end{array}$ & $\begin{array}{l}\text { Inspect the dispersion of nanometer-sized materials } \\
\text { and characterize their superficial nanostructures and } \\
\text { interfaces }\end{array}$ \\
\hline 5 & Dynamic light scattering & $\begin{array}{l}\text { Measure the average size and size distribution of } \\
\text { nanometer-sized materials }\end{array}$ \\
\hline 6 & Viscometer & Measure the dynamic viscosity of sampling materials \\
\hline 7 & Hydrometer & Measure the density of sampling materials \\
\hline 8 & $\begin{array}{l}\text { Fourier transform infrared } \\
\text { (FTIR) spectrometer }\end{array}$ & $\begin{array}{l}\text { Obtain the infrared spectra and determine the } \\
\text { chemical compatibility of sampling materials }\end{array}$ \\
\hline 9 & X-Ray Diffraction (XRD) & $\begin{array}{l}\text { Measure the crystallite size and structure of } \\
\text { nanometer-sized materials }\end{array}$ \\
\hline 10 & $\begin{array}{l}\text { Thermal gravimetric analyzer } \\
\text { (TGA) }\end{array}$ & Determine the thermal stability of sampling materials \\
\hline
\end{tabular}


Table 2 Summary of major nano-enhanced PCMs and key findings from the literature

\begin{tabular}{|c|c|c|c|c|c|c|c|}
\hline \multirow[b]{2}{*}{ No } & \multirow[b]{2}{*}{ References } & \multicolumn{2}{|c|}{ Phase change materials } & \multicolumn{3}{|c|}{ Nanometer-sized materials } & \multirow[b]{2}{*}{ Key findings } \\
\hline & & $\begin{array}{l}\text { Material } \\
\text { used }\end{array}$ & $\begin{array}{l}\text { Phase change } \\
\text { temperature }\end{array}$ & Materials used & Fraction & Size & \\
\hline 1 & Wu et al. [19] & Paraffin & $58-60^{\circ} \mathrm{C}$ & $\begin{array}{l}\text { Copper } \\
\text { particles }\end{array}$ & 2 wt. $\%$ & $25 \mathrm{~nm}$ & $\begin{array}{l}\text { Thermal conductivity enhancement was } \\
14.2 \% \text { in solid state and } 18.1 \% \text { in liquid } \\
\text { state }\end{array}$ \\
\hline \multirow[t]{2}{*}{2} & \multirow{2}{*}{$\begin{array}{l}\text { Teng and } \mathrm{Yu} \\
{[28]}\end{array}$} & \multirow[t]{2}{*}{ Paraffin } & \multirow[t]{2}{*}{$55-65^{\circ} \mathrm{C}$} & $\begin{array}{l}\text { Alumina, } \\
\text { titania, and } \\
\text { silica particles }\end{array}$ & $\begin{array}{l}1,2 \text { and } 3 \\
\text { wt. } \%\end{array}$ & $20-30 \mathrm{~nm}$ & \multirow{2}{*}{$\begin{array}{l}\text { Titania is more effective than the others in } \\
\text { modifying the heat conduction and thermal } \\
\text { storage performance of paraffin. }\end{array}$} \\
\hline & & & & $\begin{array}{c}\text { Zinc oxide } \\
\text { particles }\end{array}$ & $\begin{array}{l}1,2 \text { and } 3 \\
\text { wt. } \%\end{array}$ & $\begin{array}{c}\text { Several hundred } \\
\text { nanometers }\end{array}$ & \\
\hline 3 & Oya et al. [29] & Erythritol & $118^{\circ} \mathrm{C}$ (Melting) & $\begin{array}{l}\text { Expanded } \\
\text { graphite } \\
\text { particles }\end{array}$ & 15 vol. $\%$ & 6 (aspect ratio 1.9) & $\begin{array}{l}\text { The thermal conductivity of the mixture } \\
\text { with expanded graphite increased by } 640 \% \text {, } \\
\text { compared to the pure PCM }\end{array}$ \\
\hline 4 & He et al. [33] & $\begin{array}{l}\text { Barium } \\
\text { chloride }\end{array}$ & $-8.0^{\circ} \mathrm{C}$ & $\begin{array}{l}\text { Titania } \\
\text { particles }\end{array}$ & $\begin{array}{c}0.07,0.13 \\
0.25 \text { and } \\
0.50 \text { wt. } \%\end{array}$ & $20 \mathrm{~nm}$ & $\begin{array}{l}\text { Thermal conductivity of the mixture } \\
\text { increased by } 12.76 \% \text { at }-5^{\circ} \mathrm{C} \text { when the } \\
\text { weight fraction of nanoparticles was } 0.50 \%\end{array}$ \\
\hline 5 & Zeng et al. [39] & 1-dodecanol & $22^{\circ} \mathrm{C}$ (Melting) & $\begin{array}{l}\text { Multi-walled } \\
\text { carbon } \\
\text { nanotubes } \\
\end{array}$ & $\begin{array}{c}1 \text { and } 2 \\
\text { wt. } \%\end{array}$ & $\begin{array}{l}\text { Length: } 0.5-2 \mu \mathrm{m} \text {, } \\
\quad \text { outer } \\
\text { diameter: } 8-15 \mathrm{~nm} \\
\end{array}$ & $\begin{array}{l}4.6 \% \text { and } 11.0 \% \text { enhancement in thermal } \\
\text { conductivity by addition of } 1 \text { and } 2 \text { wt. } \% \text { of } \\
\text { CNTs, respectively }\end{array}$ \\
\hline 6 & Ho and Gao [41] & n-octadecane & $25.1-26.5^{\circ} \mathrm{C}$ & $\begin{array}{l}\text { Alumina } \\
\text { particles }\end{array}$ & $\begin{array}{l}5 \text { and } 10 \\
\text { wt. } \%\end{array}$ & $\begin{array}{c}159.6 \mathrm{~nm}(5 \mathrm{wt} . \%) \text { and } \\
196 \mathrm{~nm}(10 \mathrm{wt} \%)\end{array}$ & $\begin{array}{l}17 \% \text { increase in thermal conductivity with } \\
10 \mathrm{wt} . \% \text { alumina at } 60^{\circ} \mathrm{C}\end{array}$ \\
\hline 7 & Li [60] & Paraffin & $28.81^{\circ} \mathrm{C}$ & $\begin{array}{l}\text { Graphite } \\
\text { particles }\end{array}$ & $\begin{array}{c}1,4,7 \text { and } \\
10 \text { wt. } \%\end{array}$ & $35 \mathrm{~nm}$ & $\begin{array}{l}4.3-167.5 \% \text { increase in thermal } \\
\text { conductivity }\end{array}$ \\
\hline \multirow[t]{2}{*}{8} & \multirow[t]{2}{*}{ Cui et al. [66] } & Paraffin wax & $52-54^{\circ} \mathrm{C}$ & $\begin{array}{l}\text { Carbon } \\
\text { nanofibers } \\
(\mathrm{CNFs}) \\
\end{array}$ & $\begin{array}{l}1,2,5 \text { and } \\
10 \text { wt. } \%\end{array}$ & $\begin{array}{l}\text { Average outer } \\
\text { diameter: } 200 \mathrm{~nm}\end{array}$ & $\begin{array}{l}24.4-40.6 \% \text { enhancement in thermal } \\
\text { conductivity }\end{array}$ \\
\hline & & Soy wax & $52-54^{\circ} \mathrm{C}$ & $\begin{array}{l}\text { CNFs and } \\
\text { CNTs }\end{array}$ & $\begin{array}{c}1,2,5 \text { and } \\
10 \text { wt. } \%\end{array}$ & $\begin{array}{l}\text { CNT: diameter, length, } \\
\text { and specific surface }\end{array}$ & $\begin{array}{l}27.8-44.8 \% \text { and } 5.9-24.4 \% \text { increases in } \\
\text { thermal conductivity by using CNFs and }\end{array}$ \\
\hline
\end{tabular}




\begin{tabular}{|c|c|c|c|c|c|c|c|}
\hline & & & & & & $\begin{array}{c}\text { area were } 30 \mathrm{~nm}, 50 \\
\mu \mathrm{m} \text {, and } 60 \mathrm{~m}^{2} / \mathrm{g}\end{array}$ & CNTs, respectively \\
\hline 9 & $\begin{array}{l}\text { Harikrishnan et } \\
\text { al. }[67]\end{array}$ & Stearic acid & $57-59^{\circ} \mathrm{C}$ & $\begin{array}{c}\text { Titania } \\
\text { particles }\end{array}$ & $\begin{array}{l}0.05,0.1 \\
0.15,0.2 \\
0.25 \text { and } \\
0.3 \text { wt. } \%\end{array}$ & $\begin{array}{l}13 \text { to } 65 \mathrm{~nm} \text { (average } \\
\text { size is } 23 \mathrm{~nm} \text { ) }\end{array}$ & $\begin{array}{l}\text { The thermal conductivity of the mixture } \\
\text { increased by } 21.05-70.53 \% \text {, as compared to } \\
\text { stearic acid }\end{array}$ \\
\hline 10 & Song et al. [68] & $\begin{array}{c}\text { Bromo- } \\
\text { hexadecane }\end{array}$ & $17-18^{\circ} \mathrm{C}$ & Silver particles & 3.0 wt. $\%$ & $\begin{array}{c}40-60 \mathrm{~nm} \text { with a } \\
\text { surface area of } 30-50 \\
\mathrm{~m} 2 / \mathrm{g}\end{array}$ & $\begin{array}{l}\text { Nano-composite PCM microcapsules have } \\
\text { higher thermal stability, compared to the } \\
\text { base fluid }\end{array}$ \\
\hline 11 & Jesumathy [73] & Paraffin wax & $\begin{array}{c}58.2^{\circ} \mathrm{C} \\
\text { (Freezing) }\end{array}$ & $\begin{array}{l}\text { Copper oxide } \\
\text { particles }\end{array}$ & $\begin{array}{l}2,5 \text { and } 10 \\
\text { wt. } \%\end{array}$ & $40 \mathrm{~nm}$ & $\begin{array}{l}\text { 6-7.8\% increase in thermal conductivity } \\
\text { and 5-30\% increase in dynamic viscosity }\end{array}$ \\
\hline 12 & $\begin{array}{c}\text { Fan and } \\
\text { Khodadadi [74] }\end{array}$ & Cyclohexane & $6.5^{\circ} \mathrm{C}$ & $\begin{array}{l}\text { Copper oxide } \\
\text { particles }\end{array}$ & $\begin{array}{l}0.5,1 \text { and } 2 \\
\quad \text { vol. } \%\end{array}$ & $5-15 \mathrm{~nm}$ & $\begin{array}{l}\text { Solidification process was expedited by } \\
8.23 \% \text { when the volume fraction of } \\
\text { nanoparticles was } 0.5 \%\end{array}$ \\
\hline 13 & $\begin{array}{l}\text { Sanusi et al. } \\
{[79]}\end{array}$ & n-tricosane & $56 \pm 2^{\circ} \mathrm{C}$ & $\begin{array}{l}\text { Herringbone } \\
\text { style graphite } \\
\text { nanofibers } \\
\text { (GNFs) }\end{array}$ & $10 \mathrm{wt} . \%$ & $\begin{array}{l}2-100 \mathrm{~nm} \text { in diameter } \\
\text { and up to } 100 \mu \mathrm{m} \text { in } \\
\text { length }\end{array}$ & $\begin{array}{l}\text { For thermal containment unit with an aspect } \\
\text { ratio of } 1,61 \% \text { decrease in solidification } \\
\text { time was achieved using herringbone GNFs } \\
\text { with a weight fraction of } 10 \% \\
\end{array}$ \\
\hline 14 & $\begin{array}{c}\text { Sciacovelli et al. } \\
\text { [83] }\end{array}$ & Paraffin wax & $37.8-44.23^{\circ} \mathrm{C}$ & $\begin{array}{l}\text { Copper } \\
\text { particles }\end{array}$ & $\begin{array}{c}0.5,1,2 \\
\text { and } 4 \text { vol. } \%\end{array}$ & $15 \mathrm{~nm}$ & $3-15 \%$ reduction in the melting time \\
\hline 15 & $\begin{array}{l}\text { EI Hasadi and } \\
\text { Khodadadi [94] }\end{array}$ & Cyclohexane & $6.5^{\circ} \mathrm{C}$ (Melting) & Copper & $\begin{array}{l}0.01,0.1 \\
\text { and } 1 \text { vol. } \%\end{array}$ & $2,3,5$ and $7 \mathrm{~nm}$ & $\begin{array}{c}\text { Transition segregation coefficient increased } \\
\text { with the decrease of the particle size and } \\
\text { increase of the volume fraction of } \\
\text { nanoparticles }\end{array}$ \\
\hline 16 & $\begin{array}{l}\text { Parameshwaran } \\
\text { et al. }[101]\end{array}$ & $\begin{array}{c}\text { Ethyl } \\
\text { cinnamate }\end{array}$ & $\begin{array}{c}6.75^{\circ} \mathrm{C} \\
\text { (Freezing), } \\
6.8^{\circ} \mathrm{C} \text { (Melting) }\end{array}$ & $\begin{array}{c}\text { Silver-titania } \\
\text { hybrid } \\
\text { nanocomposite }\end{array}$ & $\begin{array}{l}0.1-1.5 \% \\
\text { wt. } \%\end{array}$ & $10-95 \mathrm{~nm}$ & $\begin{array}{l}\text { The solidification and melting times of the } \\
\text { mixture reduced by } 23.9 \% \text { and } 8.5 \% \\
\text { respectively, when the mass fraction of the } \\
\text { silver-titania hybrid nano-composite was } \\
1.5 \%\end{array}$ \\
\hline
\end{tabular}


Table 3 Thermo-physical properties of the PCM and copper particles

\begin{tabular}{lll}
\hline & RT24 [107] & Copper nanoparticles [87] \\
\hline \hline Phase change temperature $\left({ }^{\circ} \mathrm{C}\right)$ & $21-25$ & - \\
Specific heat capacity $(\mathrm{J} / \mathrm{kg} \cdot \mathrm{K})$ & 2,000 & 383 \\
Density $\left(\mathrm{kg} / \mathrm{m}^{3}\right)$ & $880($ solid $) / 770$ (liquid) & 8,954 \\
Thermal conductivity $(\mathrm{W} / \mathrm{m} \cdot \mathrm{K})$ & 0.2 & 400 \\
Heat of fusion $(\mathrm{J} / \mathrm{kg})$ & 150,000 & - \\
\hline
\end{tabular}

Table 4 Comparison of total heat charged in and discharged from the PCM layers

\begin{tabular}{lcc}
\hline & Pure PCM & Nano-enhanced PCM \\
\hline \hline Total heat absorbed $(\mathrm{kWh})$ & 22.03 & 23.85 \\
Difference $(\mathrm{kWh})$ & - & 1.82 \\
Difference $(\%)$ & - & $8.3 \%$ \\
Total heat discharged $(\mathrm{kWh})$ & 8.52 & 10.66 \\
Difference $(\mathrm{kWh})$ & - & 2.14 \\
Difference $(\%)$ & - & $25.1 \%$ \\
\hline
\end{tabular}




\section{Figure Captions}

Fig. 1 Framework towards using nano-enhanced PCMs in buildings

Fig. 2 Solar Decathlon house concerned in this study

Fig. 3 PCM enhanced ceiling ventilation system with solar PVT collectors

Fig. 4 Weather data under four consecutive winter days, Sydney

Fig. 5 Percentages of thermal energy stored in pure PCM and nano-enhanced PCM layers

Fig. 6 Outlet air temperature from PVT collectors and PCM layers 


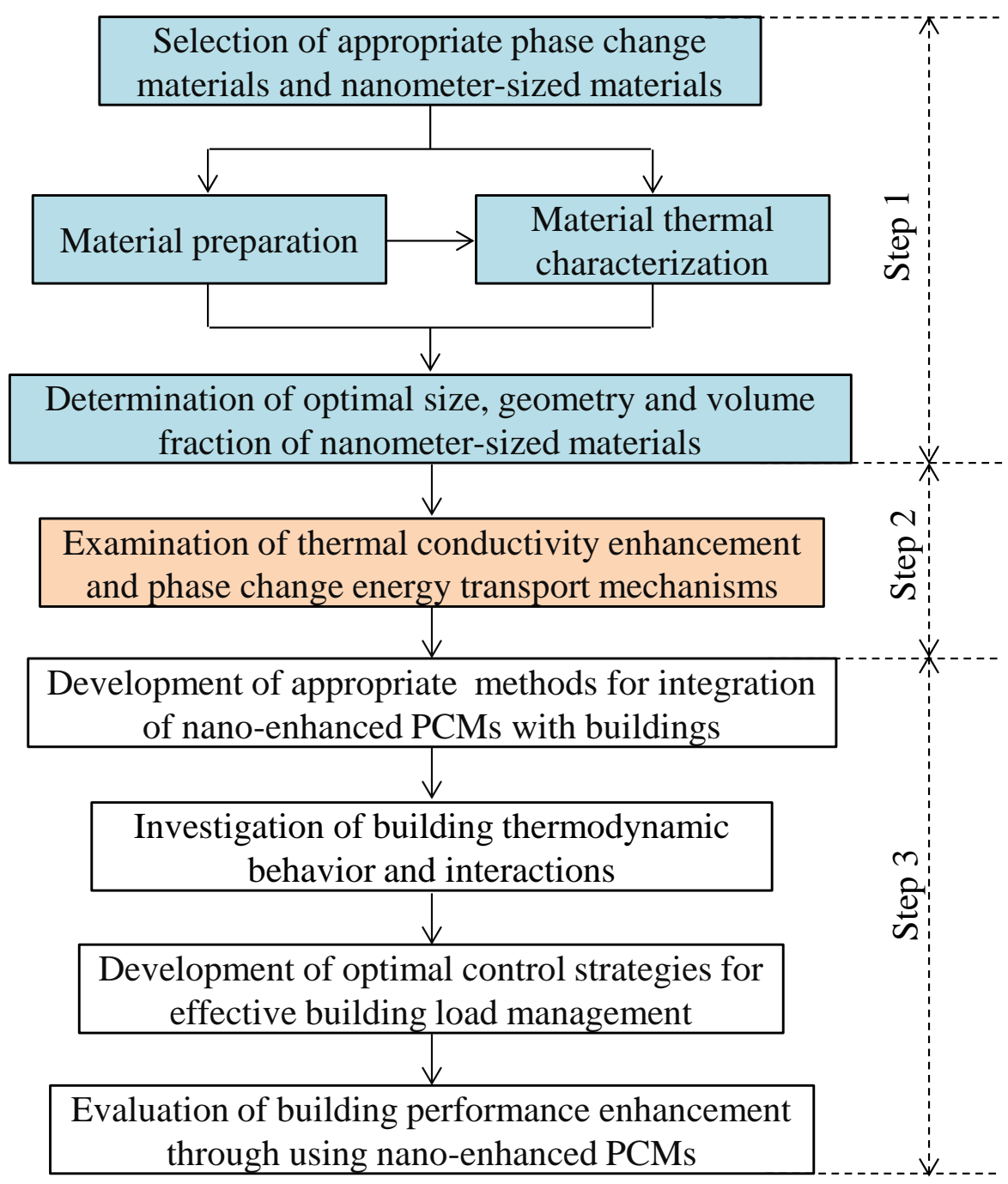

Fig. 1 Framework towards using nano-enhanced PCMs in buildings. 


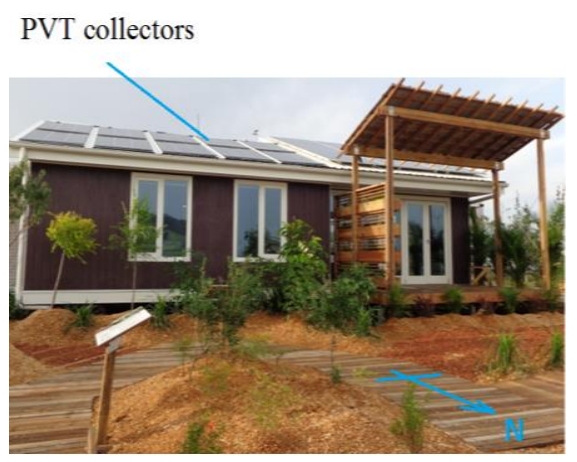

a) Outlook of the house

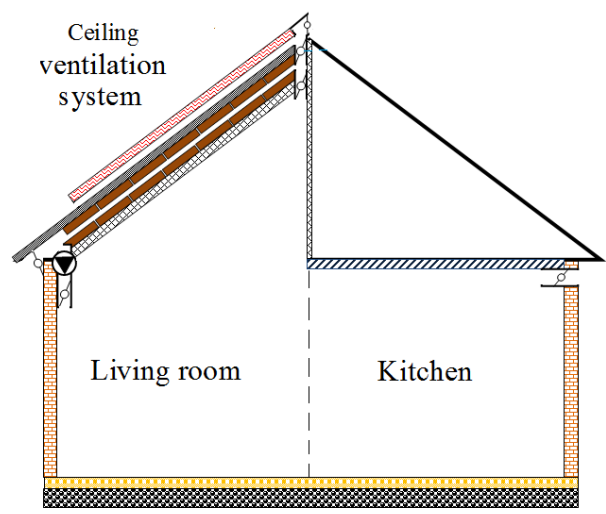

b) Cross section of the kitchen, dinning room and living room

Fig. 2 Solar Decathlon house concerned in this study.

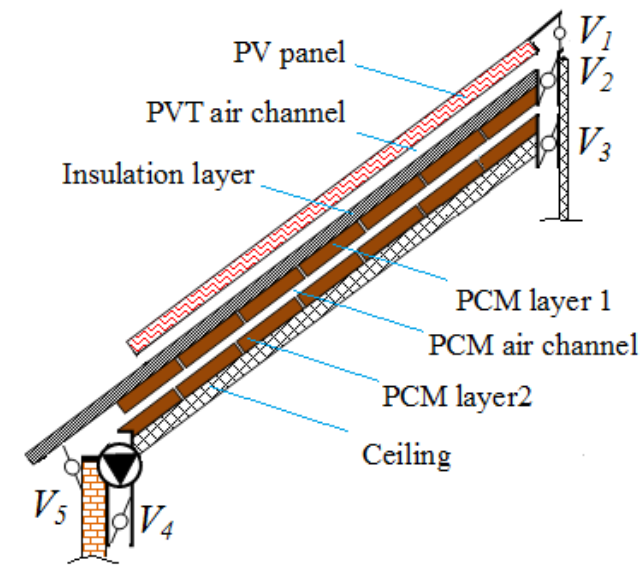

Fig. 3 PCM enhanced ceiling ventilation system with solar PVT collectors. 


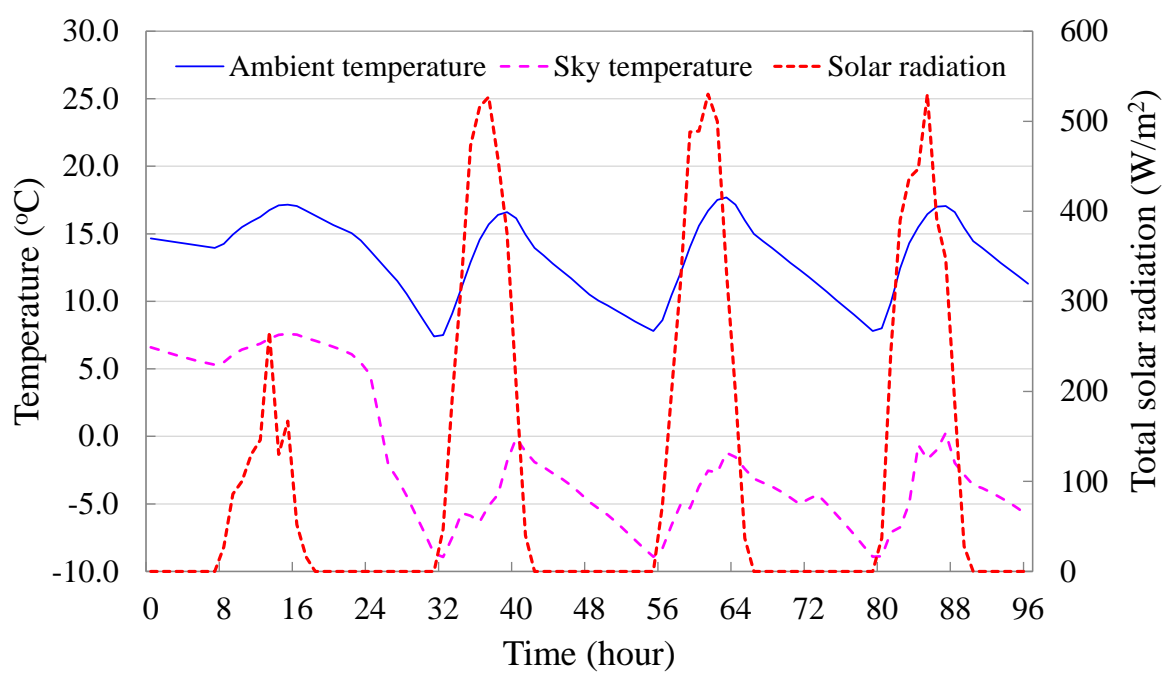

Fig. 4 Weather data under four consecutive winter days, Sydney.

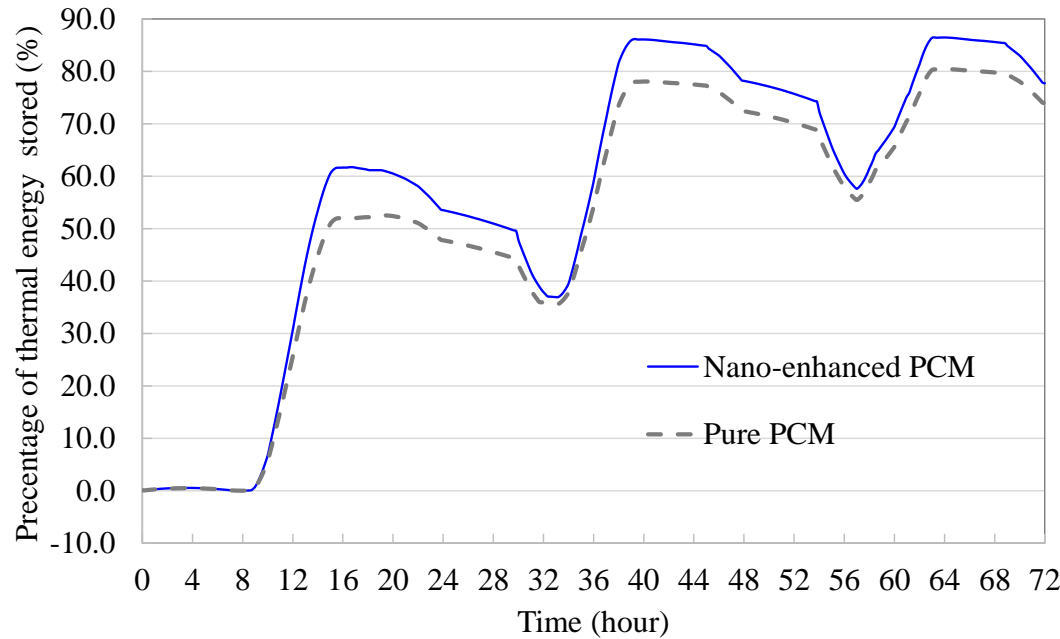

Fig. 5 Percentages of thermal energy stored in pure PCM and nano-enhanced PCM layers. 


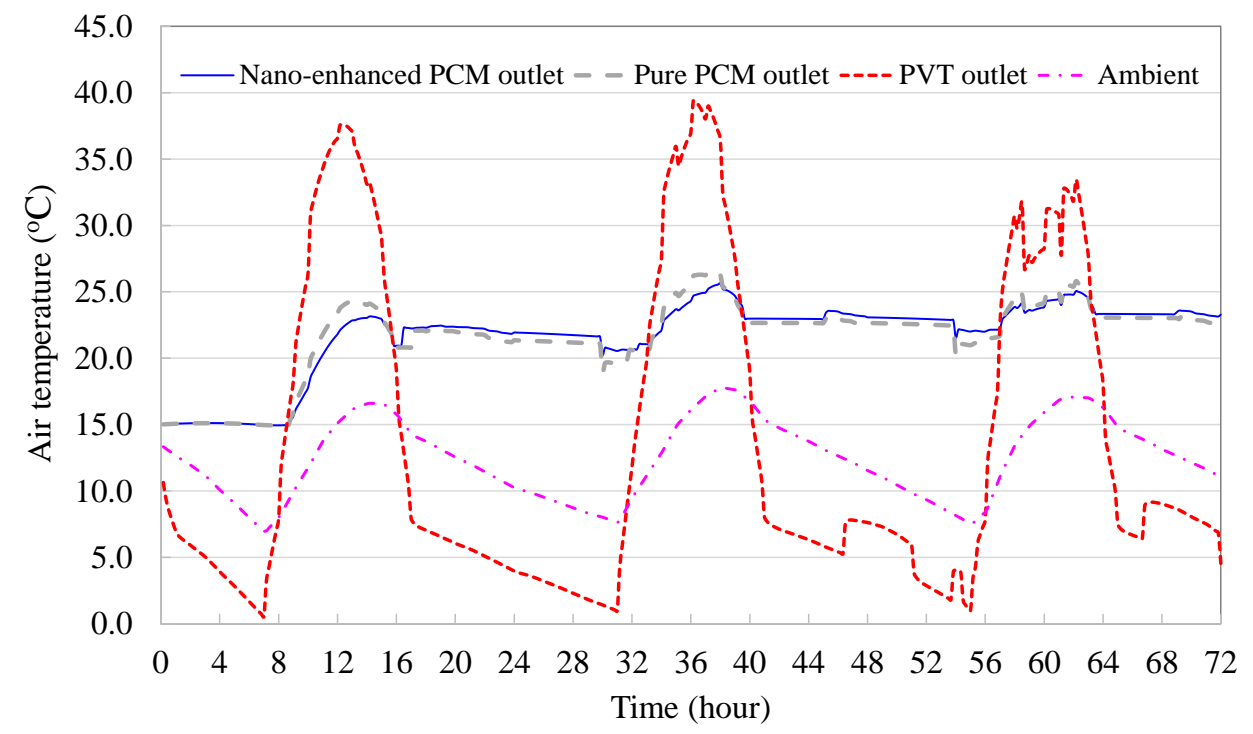

Fig. 6 Outlet air temperature from PVT collectors and PCM layers. 